Research Article

\title{
Simulation and Experimental Study on Drying Process of the Household Gas Clothes Dryer
}

\author{
Xiao-mei Huang $\mathbb{D D}^{1,2,3}$ Yi Zhao $\mathbb{D}^{1}{ }^{1}$ and Hui-qing Liu $\mathbb{D}^{4}$ \\ ${ }^{1}$ School of Civil Engineering, Chongqing University, Chongqing, China \\ ${ }^{2}$ Key Laboratory of Three Gorges Reservoir Region's Eco-Environment, Ministry of Education, Chongqing, China \\ ${ }^{3}$ Joint International Laboratory of Green Building and Built Environments, Ministry of Education, Chongqing, China \\ ${ }^{4}$ Ningbo FOTILE Kitchenware Co., Ltd., Ningbo, China \\ Correspondence should be addressed to Xiao-mei Huang; hxm1980@cqu.edu.cn
}

Received 3 June 2019; Accepted 8 October 2019; Published 27 November 2019

Academic Editor: Vasilis Burganos

Copyright (C) 2019 Xiao-mei Huang et al. This is an open access article distributed under the Creative Commons Attribution License, which permits unrestricted use, distribution, and reproduction in any medium, provided the original work is properly cited.

\begin{abstract}
This paper analyzed the drying process of the household gas clothes dryer (GCD) based on the principle of heat and mass transfer. The drying models in three scenarios were established: natural gas burned in combustion chamber, ambient air mixed with exhausted gas in hot gas duct, and clothes were dried in the drying drum. The simulation of the drying process was performed on MATLAB software. And the effectiveness of the drying model was verified by comparison with experiment results. The effects of gas flow rate, dry mass of clothes, ambient temperature, ambient humidity, textile type, and moisture extraction rate (MER) on the performance of dryers were studied. This paper provided a theoretical basis for the design and optimization of GCDs. It was found that the drying time of the gas clothes dryer was mostly affected by the gas flow and dry mass of clothes, and the specific moisture extraction rate (SMER) was mostly affected by the ambient temperature and relative humidity. The nylon clothes have the fastest MER and the smallest SMER. Moreover, reducing operating time in falling-rate drying period can improve energy efficiency.
\end{abstract}

\section{Introduction}

Clothes dryers (CDs) have become the basic necessities of life for ordinary families in developed countries, and they will gradually enter Chinese market with Chinese socioeconomic progress [1]. At present, the majority of Chinese households use electric clothes dryers (ECDs), in which resistance wires are used to heat the air to $60-80^{\circ} \mathrm{C}$. Since electricity is a kind of quality energy, it is an energy-wasting way to dry clothes by low-temperature heating method of the ECD. Furthermore, bacteria cannot be completely killed under such low temperature [2]. It is reported that household ECDs are one of the most energy-consuming appliances in the developed countries [3]. For example, domestic CDs are responsible for approximately $9 \%$ of the residential electrical energy consumption in the United States. Household ECDs increase electricity consumption and thus aggravates air pollution in countries which rely on coal-fired power generation such as China. On the other hand, gas clothes dryers (GCDs) heat the air and dry the clothes with the thermal energy released by natural gas. Natural gas is a kind of environmental-friendly primary energy, and it has much less negative effect on the environment than using electricity generated from coal. Therefore, GCDs are quite popular in developed countries due to its advantages of being energy-efficient, economic, and clean.

The GCD consists of five parts, including a bottom cabinet, a combustor, a hot gas duct, a drying drum, and an exhaust fan. The operating procedure of the GCD is shown in Figure 1. The exhaust fan creates a negative pressure in the system, and so the ambient air is drawn into the bottom cabinet under the pressure difference. A part of air from the bottom cabinet is drawn into the combustor as primary air by ejection to premix with natural gas. The secondary air enters the combustor under the pressure difference, and then combustion reaction takes place between the premixed natural gas and the secondary air. Another part of ambient air from the bottom cabinet mixes with the high-temperature exhaust gas in the hot gas duct to cool the exhaust gas 


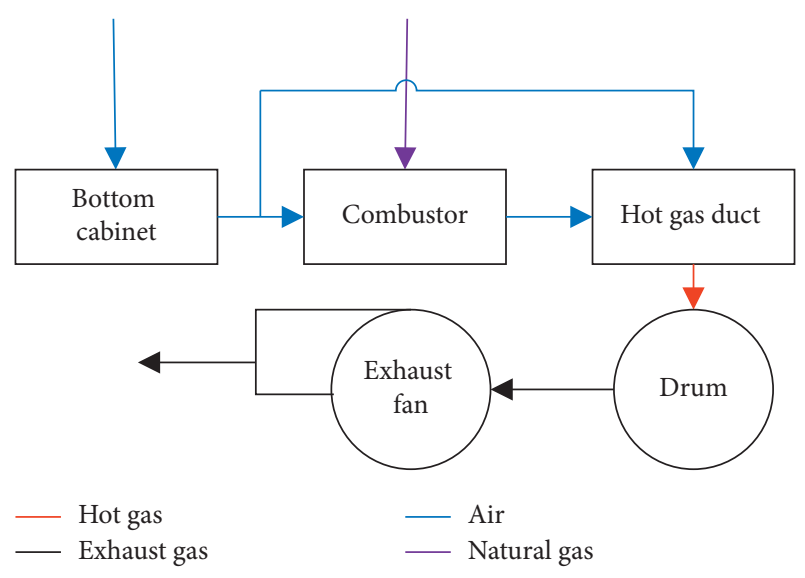

Figure 1: Operating procedure of the GCD.

down to certain temperature suitable for drying clothes. Then, the mixed hot gas in the hot gas duct is drawn into the drum. Wet clothes rotate within the drum and keep good contact with the hot gas to enhance the heat and mass transfer between the wet clothes and hot gas. Finally, the humidified gas exits the dryer via the exhaust fan.

In the past decades, many researchers have focused on the dehydration model of drying process. But most research studies focus on adopting an empirical or a semiempirical approach, and the further study of heat and mass exchange principle during drying process was neglected. Tranxuan and Deans [4] utilized the modified convective transport equation to calculate the mass transfer at the air-clothes interface. Nordon and David [5] used a mathematical model to describe coupled diffusion of heat and mass transfer and studied the rate of moisture exchange between the solid and gaseous phases. However, they neglected the moisture content on the clothes surface. Lambert et al. [6] defined the water activity to illustrate the moisture content of the medium to be dried. Deans [7] improved Lambert's model in which the use of the desorption isotherm model replaces the analogous method based on drying curves. Yi et al. [3] developed a physics-based model for thin clothes. The water activity coefficient was expressed as a function of cloth type, mass transfer rate, water latent heat, and cloth temperature using statistical mechanics, instead of using mathematical approximations of the sorption isotherms. The proposed model was validated using two different fabric types with the experimental data and the results of Deans's literature [7]. However, the effect of the clothes could not be reproduced when the clothes are too heavy or too light. Bassily and Colver [8] conducted an energy performance analysis by changing operating parameters including heater power, fan speed, drum speed, mass, and initial moisture content of the clothes for 32 runs. Techniques are proposed to improve the energy efficiency. To further obtain a measure of efficiency of the mass transfer process, Bassily and Colver [9] developed an "ideal" mass transfer process. A stretched, wet piece of fabric was held perpendicular to an incoming airstream. However, the comparison between the actual and the ideal process showed that the mass transfer efficiency averaged $26.4 \%$ during the 32 experimental runs. Sherwood [10] focused on the drying process in solid materials. The case of drying by internal diffusion of liquid to the surface, with negligible resistance to the removal of vapor, is discussed in detail. Newton's law of diffusion in an infinite sheet was solved to characterize the moisture gradients during drying of a slab of material, and a simplified equation was derived to calculate the theoretical liquid distribution at anytime in a material where internal liquid diffusion controls the drying. The results of the theoretical drying equation fit reasonably well with the experimental data for drying of wood and clay for constant drying conditions. Sherwood [11] provided a simple empirical equation to fit the data reasonably well in the falling rate period later and to afford a simple basis of calculation in the dryer design. The effects of adjoining dry surfaces, radiation from the surroundings, and air velocity on the rate of drying of solids in the constant rate-of-drying period are described. The falling rate period is shown to be in general divisible into two zones: in the first the rate of drying decreases because of a decrease in the wetted surface, and in the second and final zone of the drying process internal liquid diffusion controls the drying. Yadav and Moon [12] used the activity coefficient to show the moisture level of the clothes surface, the activity coefficient is assumed to be a constant in the simulation. However, during experiment, the value of the activity coefficient changes with the change in the moisture level and temperature of the clothes as the drying progresses. Delshad and Thomas [13] proposed a model of a wood drying process to describe the moisture content and temperature behavior of timber inside a drying kiln. Although this model was based on the energy balance equations, the moisture content behavior of the wood surface over time was not taken into consideration. It is obvious that most of these research studies are purely empirical or semiempirical. The principle of heat and mass transfer in drying process has not been studied thoroughly. $\mathrm{Ng}$ and Deng [14] developed a termination control method for a $\mathrm{CD}$ using the equilibrium moisture content in ambient environment as a termination point. Its mathematical model using a "semiempirical" approach and overlooked the temperature-rise period. Gluesenkamp et al. [15] used the heat and mass transfer effectiveness model along with the empirical data from several different clothes dryers to develop an accurate and versatile correlation that can easily be applied to the modeling and simulation of clothes dryer performance.

In this study, heat and mass transfer principle of water transfer process is described and mathematical models of drying process are derived. The whole simulation platform is performed on MATLAB software, and the simulation results are verified with the corresponding experiments.

\section{Theoretical Modeling of the Drying Process in a GCD}

2.1. Simplified Hypothesis. The drying process of clothes dryers (CDs) can be expressed by the continuous variation of the clothes temperature and moisture content with time. The mean value of the variable can be obtained by solving a related difference equation of the heat and moisture transfer in porous medium. But the numerical value of transfer 
coefficient is necessary to solve the difference equation. As the heat transfer coefficient and mass transfer coefficient vary with time, the difference equation representing the drying process is nonlinear, so it is difficult to solve the difference equation [16]. In order to simulate the drying process in a $\mathrm{CD}$ with the mathematical model, the following simplified assumptions were made in the discrete time and space on the basis of the existing literature $[12,17]$ :

(i) The dried hot gas flow axially passes the drum, and we assume its characteristics are considered same as that of air

(ii) During the drying process, the clothes rotates with the drum and the activity coefficients are uniformly distributed in space, including the temperature, moisture content, specific heat, and the water diffusivity of the clothes

(iii) During the drying time step $\Delta t$, the clothes temperature, drum temperature, and moisture temperature of the clothes are identical, and the moisture content of the saturated air layer near the clothes surface is identical

(iv) In the drying process, the heat and mass transfer coefficient of the air layer adjacent to the clothes are constant, and the moisture level of the clothes surface is represented by the activity coefficient

2.2. Combustion Model of GCD. In this paper, the combustion reaction of natural gas is simplified as the combustion reactions of methane, ethane, and propane. The reaction equations are as follows:

$$
\begin{aligned}
\mathrm{CH}_{4}+2 \mathrm{O}_{2} & =\mathrm{CO}_{2}+2 \mathrm{H}_{2} \mathrm{O} \\
2 \mathrm{C}_{2} \mathrm{H}_{6}+7 \mathrm{O}_{2} & =4 \mathrm{CO}_{2}+6 \mathrm{H}_{2} \mathrm{O} \\
\mathrm{C}_{3} \mathrm{H}_{8}+5 \mathrm{O}_{2} & =3 \mathrm{CO}_{2}+4 \mathrm{H}_{2} \mathrm{O}
\end{aligned}
$$

Natural gas and air enter the combustion chamber in a certain proportion, and the heat in chamber consists of two parts. One part is the enthalpy of natural gas and air, and another part is the calorific value [18] of natural gas. Except the dissipated heat, the two parts are used to heat the exhaust gas and become the enthalpy of the exhaust gas. According to the enthalpy equilibrium, the enthalpy equations before and after combustion are shown as follows:

$$
\begin{aligned}
H_{f}= & V_{0, \mathrm{CH}_{4}} H_{l, \mathrm{CH}_{4}}+V_{0, \mathrm{C}_{2} \mathrm{H}_{6}} H_{l, \mathrm{C}_{2} \mathrm{H}_{6}}+V_{0, \mathrm{C}_{3} \mathrm{H}_{8}} H_{l, \mathrm{C}_{3} \mathrm{H}_{8}} \\
& +H_{g}+H_{a, \text { react }}, \\
H_{g}= & \sum m c_{g} t_{g}=\left(m_{\mathrm{CH}_{4}} c_{p, \mathrm{CH}_{4}}+m_{\mathrm{C}_{2} \mathrm{H}_{6}} c_{p, \mathrm{C}_{2} \mathrm{H}_{6}}\right. \\
& \left.+m_{\mathrm{C}_{3} \mathrm{H}_{8}} c_{p, \mathrm{C}_{3} \mathrm{H}_{8}}\right) T_{g}, \\
H_{a, \text { react }}= & m_{a, \text { react }}\left(c_{p, a}+c_{p, w} d_{a}\right) T_{a}, \\
m_{a, \text { react }}= & \frac{254.56 \cdot m_{\mathrm{CH}_{4}}}{16}+\frac{960.96 \cdot m_{\mathrm{C}_{2} \mathrm{H}_{6}}}{60}+\frac{686.4 \cdot m_{\mathrm{C}_{3} \mathrm{H}_{8}}}{44},
\end{aligned}
$$

where $H_{l, \mathrm{CH}_{4}}, H_{l, \mathrm{C}_{2} \mathrm{H}_{6}}$, and $H_{l, \mathrm{C}_{3} \mathrm{H}_{8}}$ are the low heat value (kJ/ $\mathrm{Nm}^{3}$ ) of $\mathrm{CH}_{4}, \mathrm{C}_{2} \mathrm{H}_{6}$, and $\mathrm{C}_{3} \mathrm{H}_{8}$, respectively. $V_{0, \mathrm{CH}_{4}}, V_{0, \mathrm{C}_{2} \mathrm{H}_{6}}$, and $V_{0, \mathrm{C}_{3} \mathrm{H}_{8}}$ are the volume flow rate $\left(\mathrm{Nm}^{3} / \mathrm{s}\right)$ of $\mathrm{CH}_{4}, \mathrm{C}_{2} \mathrm{H}_{6}$, and $\mathrm{C}_{3} \mathrm{H}_{8}$, respectively, under standard state. $m_{\mathrm{CH}_{4}}, m_{\mathrm{C}_{2} \mathrm{H}_{6}}$, and $m_{\mathrm{C}_{3} \mathrm{H}_{8}}$ are the mass flow rate $(\mathrm{kg} / \mathrm{s})$ of $\mathrm{CH}_{4}, \mathrm{C}_{2} \mathrm{H}_{6}$, and $\mathrm{C}_{3} \mathrm{H}_{8}$, respectively. $c_{p, \mathrm{CH}_{4}}, c_{p, \mathrm{C}_{2} \mathrm{H}_{6}}$, and $c_{p, \mathrm{C}_{3} \mathrm{H}_{8}}$ are the specific heat of $\mathrm{CH}_{4}, \mathrm{C}_{2} \mathrm{H}_{6}$, and $\mathrm{C}_{3} \mathrm{H}_{8}$, respectively, at constant pressure. $H_{g}$ is the enthalpy $(\mathrm{kJ} / \mathrm{s})$ of natural gas. $H_{a \text {,react }}$ is the physical heat $(\mathrm{kJ})$ brought by air which takes part in complete combustion. $H_{f}$ is the enthalpy $(\mathrm{kJ})$ of exhaust gas produced by complete combustion. $m_{a \text {,react }}$ is the mass flow rate $(\mathrm{kJ} / \mathrm{s})$ of dry air participating in the combustion reaction; $c_{v}$ is the specific heat of water vapor at constant pressure $(1.84 \mathrm{~kJ} /$ $(\mathrm{kg} \cdot \mathrm{K})) \cdot c_{p, w}$ is the specific heat of water at constant pressure $(4.19 \mathrm{~kJ} /(\mathrm{kg} \cdot \mathrm{K})), c_{p, a}$ is the specific heat of air at constant pressure $(1.01 \mathrm{~kJ} /(\mathrm{kg} \cdot \mathrm{K})), d_{a}$ is the moisture content of the air ( $\mathrm{kg} / \mathrm{kg}$ dry air), and $T_{q}$ and $T_{a}$ are the natural gas temperature and air temperature $\left({ }^{\circ} \mathrm{C}\right)$, respectively.

2.3. Modeling of Mixing Process of Exhaust Gas in Hot Gas Duct. The hot gas duct that connects the combustion chamber with the drum is taken as a study object. The heat in the hot gas duct includes the enthalpy of exhaust gas incomplete combustion, the enthalpy of mixed air, and the heat transferred by convection of drying drum and air. The heat flowing out of the hot gas duct includes the enthalpy of dried hot gas at the drying drum inlet and the heat loss in the hot gas duct. According to the energy conservation law, the enthalpy equilibrium of the exhaust gas and air mixing process in the hot gas duct is as follows:

$$
H_{f}+H_{a \text {, mix }}+Q_{D}=H_{\text {in }}+Q_{\text {lossrfd }} \text {, }
$$

where $H_{f}$ is the enthalpy (kJ) of exhaust gas incomplete combustion, $H_{a \text {,mix }}$ is the enthalpy (kJ) of mixed air, $Q_{D}$ is the heat exchange $(\mathrm{kJ})$ between drying drums and air, $H_{\text {in }}$ is the enthalpy $(\mathrm{kJ})$ of dried hot gas at the drying drum's inlet, and $Q_{\text {lossrfd }}(\mathrm{kJ})$ is heat loss in the hot gas duct.

The exhaust gas mainly consists of nitrogen, carbon dioxide, and water. In the drying process, the air mass flow rate is variable, resulting in the component proportion in the exhaust gas. Considering that the thermophysical properties between the exhaust gas and air are similar (see Tables 1 and 2 [19]), the exhaust gas is treated as air. The advantage of this methodology is that it is easy to calculate the enthalpy of exhaust gas when lack of the actual thermophysical properties of exhaust gas and ensure the integrity of the mixing process modeling in the hot gas duct. The disadvantage of this simplification is that deviation might exist and inevitably have some effect on the modeling.

The mass flow rate of air refers to the mass flow rate of dry air. The enthalpy of mixed air can be solved as follows:

(i) Use "multifunctional measuring instrument testo 480 " and temperature-humidity recorder to simultaneously record the air velocity, temperature, and relative humidity at the moisture outlet of the dryer. Check Chemistry and Chemical Industry Property Parameter Manual [19] (see Table 2.2.2) to 
TABLE 1: The thermophysical properties of exhaust gas under atmospheric pressure $\left(p=1.101325 \times 10^{5} \mathrm{~Pa}\right)$ (the mass fraction of exhaust gas composition is $w_{\mathrm{CO}_{2}}=13 \%, w_{\mathrm{H}_{2} \mathrm{O}}=11 \%$, and $\left.w_{\mathrm{N}_{2}}=76 \%\right)$.

\begin{tabular}{|c|c|c|c|c|c|c|}
\hline$t\left({ }^{\circ} \mathrm{C}\right)$ & $\rho\left(\mathrm{kg} \cdot \mathrm{m}^{-3}\right)$ & $c_{p}(\mathrm{~kJ} /(\mathrm{kg} \cdot \mathrm{K}))$ & $\lambda \times 10^{2}(\mathrm{~W} /(\mathrm{m} \cdot \mathrm{K}))$ & $a \times 10^{6}\left(\mathrm{~m}^{2} / \mathrm{s}\right)$ & $\eta \times 10^{6}(\mathrm{~Pa} \cdot \mathrm{s})$ & $v \times 10^{6}\left(\mathrm{~m}^{2} / \mathrm{s}\right)$ \\
\hline 0 & 1.295 & 1.043 & 2.278 & 16.889 & 15.78 & 12.20 \\
\hline 100 & 0.950 & 1.068 & 3.126 & 30.833 & 20.39 & 21.54 \\
\hline 200 & 0.748 & 1.097 & 4.010 & 48.889 & 24.49 & 32.80 \\
\hline 300 & 0.617 & 1.122 & 4.835 & 69.889 & 28.23 & 45.81 \\
\hline 400 & 0.525 & 1.151 & 5.695 & 94.278 & 31.68 & 60.38 \\
\hline 500 & 0.457 & 1.185 & 6.555 & 121.139 & 34.84 & 76.30 \\
\hline 600 & 0.405 & 1.214 & 7.415 & 150.889 & 37.85 & 93.61 \\
\hline 700 & 0.363 & 1.239 & 8.263 & 183.806 & 40.68 & 112.10 \\
\hline 800 & 0.330 & 1.264 & 9.147 & 219.694 & 43.37 & 131.80 \\
\hline 900 & 0.301 & 1.290 & 10.010 & 257.972 & 45.90 & 152.50 \\
\hline 1000 & 0.275 & 1.306 & 10.890 & 303.333 & 48.35 & 174.30 \\
\hline 1100 & 0.257 & 1.323 & 11.740 & 345.556 & 50.69 & 197.10 \\
\hline 1200 & 0.240 & 1.340 & 12.610 & 392.500 & 52.98 & 221.00 \\
\hline
\end{tabular}

TABLE 2: The thermophysical properties of air under atmospheric pressure $\left(p=1.101325 \times 10^{5} \mathrm{~Pa}\right)$.

\begin{tabular}{|c|c|c|c|c|c|c|}
\hline$t\left({ }^{\circ} \mathrm{C}\right)$ & $\rho\left(\mathrm{kg} \cdot \mathrm{m}^{-3}\right)$ & $c_{p}(\mathrm{~kJ} /(\mathrm{kg} \cdot \mathrm{K}))$ & $\lambda \times 10^{2}(\mathrm{~W} /(\mathrm{m} \cdot \mathrm{K}))$ & $a \times 10^{6}\left(\mathrm{~m}^{2} / \mathrm{s}\right)$ & $\eta \times 10^{6}(\mathrm{~kg} /(\mathrm{m} \cdot \mathrm{s}))$ & $v \times 10^{6}\left(\mathrm{~m}^{2} / \mathrm{s}\right)$ \\
\hline 0 & 1.293 & 1.010 & 2.442 & 19.1 & 17.2 & 13.28 \\
\hline 100 & 0.946 & 1.022 & 3.210 & 33.7 & 21.9 & 23.13 \\
\hline 200 & 0.746 & 1.034 & 3.931 & 51.6 & 26.0 & 34.85 \\
\hline 300 & 0.615 & 1.047 & 4.605 & 72.3 & 29.7 & 48.33 \\
\hline 400 & 0.524 & 1.068 & 5.210 & 95.1 & 33.0 & 63.09 \\
\hline 500 & 0.456 & 1.072 & 5.745 & 119.0 & 36.2 & 79.38 \\
\hline 600 & 0.404 & 1.089 & 6.222 & 143.0 & 39.1 & 96.89 \\
\hline 700 & 0.362 & 1.102 & 6.711 & 166.0 & 41.8 & 115.40 \\
\hline 800 & 0.329 & 1.114 & 7.176 & 190.0 & 44.3 & 134.80 \\
\hline 900 & 0.301 & 1.127 & 7.630 & 214.0 & 46.7 & 155.10 \\
\hline 1000 & 0.277 & 1.139 & 8.071 & 237.0 & 49.0 & 177.10 \\
\hline 1100 & 0.257 & 1.152 & 8.502 & 276.2 & 51.2 & 199.30 \\
\hline 1200 & 0.239 & 1.164 & 9.153 & 316.5 & 53.5 & 233.70 \\
\hline
\end{tabular}

$\rho$ : density, $\mathrm{kg} \cdot \mathrm{m}^{-3} ; c_{p}:$ specific heat at constant pressure, $\mathrm{kJ} /(\mathrm{kg} \cdot \mathrm{K}) ; \lambda$ : thermal conductivity, $\mathrm{W} /(\mathrm{m} \cdot \mathrm{K}) ; a$ : thermal diffusivity, $\mathrm{m}^{2} / \mathrm{s} ; \eta$ : viscosity, $\mathrm{kg} /(\mathrm{m} \cdot \mathrm{s}) ; \nu$ : kinematic viscosity, $\mathrm{m}^{2} / \mathrm{s}$.

obtain corresponding density of air at moisture outlet under different temperatures. The calculation software of enthalpy-humidity graph is used to obtain moisture content at certain temperatures and relative humidity.

(ii) Calculate the mass flow rate of air and average the results. Then, calculate the mass flow rate of mixed air.

(iii) Calculate the enthalpy of mixed air.

$$
\begin{aligned}
c m_{\text {out }, \text { wet }} & =V_{\text {out }} \rho_{\text {out }}=\frac{\pi d^{2}}{4} v \rho_{\text {out }}, \\
m_{\text {out }} & =\frac{1}{1+d_{\text {out }}} m_{\text {out.wet }}, \\
m_{\text {out }} & =m_{\text {in }} \\
m_{a, \text { mix }} & =m_{\text {in }}-m_{a, \text { react }}, \\
H_{a, \text { mix }} & =m_{a, \text { mix }}\left(c_{p, a}+c_{p, w} d_{a}\right) T_{a},
\end{aligned}
$$

where $m_{\text {out,wet }}$ is the mass flow rate $(\mathrm{kg} / \mathrm{s})$ of humid air at the dryer moisture outlet, $V_{\text {out }}$ is the volume flow rate $\left(\mathrm{m}^{3} / \mathrm{s}\right)$ of humid air at the dryer moisture outlet, $\rho_{\text {out }}$ is the air density $\left(\mathrm{kg} / \mathrm{m}^{3}\right)$ at the dryer moisture outlet, $d$ is the diameter $(0.07 \mathrm{~m})$ of the dryer moisture outlet, $v$ is the flow rate $(\mathrm{m} / \mathrm{s})$ of the dryer moisture outlet, $d_{\text {out }}$ is the moisture content $(\mathrm{kg} /$ $\mathrm{kg}$ dry air) of the dryer moisture outlet, $m_{\text {out }}$ is the mass flow rate of air $(\mathrm{kg} / \mathrm{s})$ at the dryer moisture outlet, $m_{\text {in }}$ is the mass flow rate of air $(\mathrm{kg} / \mathrm{s})$ at the drying drum inlet, $m_{a \text {, mix }}$ is mass flow rate $(\mathrm{kg} / \mathrm{s})$ of the mixed air, and $H_{a, \text { mix }}$ is enthalpy $(\mathrm{kJ})$ of the mixed air.

The convective heat transfer between the drying drum and the air can be expressed as follows:

$$
Q_{D}=c_{p, a} m_{\text {in }}\left(T_{D}-T_{a}\right)
$$

where $Q_{D}$ is the convective heat transfer $(\mathrm{kJ})$ between the drying drum and the air, $c_{p, a}$ is the specific heat of air at constant pressure $(1.01 \mathrm{~kJ} /(\mathrm{kg} \cdot \mathrm{K}))$, and $T_{D}$ is the temperature $\left({ }^{\circ} \mathrm{C}\right)$ of the drying drum.

The total enthalpy consists of the enthalpy of exhaust gas, the enthalpy of mixed air, and the convective heat transfer between the drying drum and the air: 


$$
H_{\text {total }}=H_{a, \text { mix }}+H_{f}+Q_{D}
$$

where $H_{\text {total }}$ is the total enthalpy which enters the drying drum.

$$
Q_{\text {lossrfd }}=F_{\text {rfd }} \cdot H_{\text {total }} \text {, }
$$

where $F_{\text {rfd }}$ is the heat loss coefficient in the hot gas duct and $Q_{\text {lossrfd }}$ is the heat loss $(\mathrm{kJ})$ in the hot gas duct.

Then, calculate the moisture content of the dry air in the drying drum inlet. The vapor comes from two sources:

(i) Alkanes' combustion produces vapor $\left(m_{\text {react }, w}\right)$.

(ii) Atmospheric air brings vapor. One part $\left(m_{a, w, 1}\right)$ is the vapor brought by the air which involves in combustion, and another part $\left(m_{a, w, 2}\right)$ is the vapor brought by the mixed air.

Use temperature-humidity recorder to record the temperature and relative humidity of the air, and use enthalpyhumidity graph calculation software to calculate moisture content $\left(d_{a}\right)$. The vapor brought by the air which involves in combustion is

$$
c m_{a, w, 1}=d_{a} m_{a, \text { react }},
$$

where $m_{a, w, 1}$ is the mass flow rate $(\mathrm{kg} / \mathrm{s})$ of vapor brought by the air which involves in combustion, $m_{a \text {,react }}$ is the mass flow rate $(\mathrm{kg} / \mathrm{s})$ of the mixed air which involves in combustion, and $d_{a}$ is the moisture content $(\mathrm{kg} / \mathrm{kg}$ dry air) of the mixed air which involves in combustion.

The vapor brought by the mixed air is

$$
m_{a, w, 2}=d_{a} m_{a, \operatorname{mix}},
$$

where $m_{a, w, 2}$ is the mass flow rate $(\mathrm{kg} / \mathrm{s})$ of vapor brought by the mixed air, $m_{a \text {,mix }}$ is the mass flow rate $(\mathrm{kg} / \mathrm{s})$ of the mixed air, and $d_{a}$ is the moisture content $(\mathrm{kg} / \mathrm{kg}$ dry air) of the mixed air.

Vapor generated from alkanes' combustion is

$$
m_{\text {react }, w}=\frac{36 \cdot m_{\mathrm{CH}_{4}}}{16}+\frac{108 \cdot m_{\mathrm{C}_{2} \mathrm{H}_{6}}}{60}+\frac{72 \cdot m_{\mathrm{C}_{3} \mathrm{H}_{8}}}{44},
$$

where $m_{\text {react, } w}$ is the mass flow rate $(\mathrm{kg} / \mathrm{s})$ of water vapor generated from alkanes' combustion and $m_{\mathrm{CH}_{4}}, m_{\mathrm{C}_{2} \mathrm{H}_{6}}$, and $m_{\mathrm{C}_{3} \mathrm{H}_{8}}$ is the mass flow rate $(\mathrm{kg} / \mathrm{s})$ of $m_{\mathrm{CH}_{4}}, m_{\mathrm{C}_{2} \mathrm{H}_{6}}$, and $m_{\mathrm{C}_{3} \mathrm{H}_{8}}$, respectively.

Hence, the moisture content of dried hot gas at the drum inlet is

$$
d_{\mathrm{in}}=\frac{m_{\mathrm{react}, w}+m_{a, w, 1}+m_{a, w, 2}}{m_{\mathrm{in}}},
$$

where $d_{\text {in }}$ is the moisture content $(\mathrm{kg} / \mathrm{kg}$ dry air) of dried hot gas at the drum inlet, $m_{a, w, 1}$ is the mass flow rate $(\mathrm{kg} / \mathrm{s})$ of water vapor brought by the air which involves in combustion reaction, $m_{a, w, 2}$ is the mass flow rate $(\mathrm{kg} / \mathrm{s})$ of water vapor brought by the mixed air, and $m_{\text {in }}$ is the air mass flow rate $(\mathrm{kg} / \mathrm{s})$ at the drum inlet.

The temperature of dried hot gas at the drum inlet is

$$
T_{\text {in }}=\frac{H_{\text {in }}}{m_{\text {in }}\left(1+d_{\text {in }}\right) c_{p, a}},
$$

where $T_{\text {in }}\left({ }^{\circ} \mathrm{C}\right)$ is the temperature of dried hot gas at the drum inlet, $H_{\text {in }}(\mathrm{kJ} / \mathrm{s})$ is the enthalpy of dried hot gas at the drum inlet, $c_{p, a}$ is specific heat of dried hot gas under constant pressure $(1.01 \mathrm{~kJ} /(\mathrm{kg} \cdot \mathrm{K}))$ at the drum inlet, and $d_{\text {in }}$ is the moisture content $(\mathrm{kg} / \mathrm{kg}$ dry air) of dried hot gas at the drum inlet.

2.4. Drying Process in Drying Drum. The drying process in drying drum is the core of clothes drying. The dried hot gas entering the drying drum exchanges heat and moisture with wet clothes; therefore, the heat is transferred to the clothes and dried hot gas takes moisture away from the clothes. In the initial period of drying process, the moisture on the clothes surface is sufficient. As the drying process progresses, the clothes surface appears to be dried to different degrees. The moisture content of the air layer adjacent to the surface of clothes is represented by the activity coefficient $(\alpha)$ :

$$
m_{\text {evap }}=k A\left[\alpha d_{m}-\frac{d_{\text {in }}+d_{\text {out }}}{2}\right] \text {, }
$$

where $m_{\text {evap }}$ is the moisture evaporation rate $(\mathrm{kg} / \mathrm{s})$ and $k$ is the mass transfer coefficient $\left(\mathrm{kg} / \mathrm{m}^{2} \cdot \mathrm{s}\right)$ of the clothes and dried hot gas, also known as the evaporation coefficient. A is the effective heat and mass transfer area $\left(\mathrm{m}^{2}\right)$ of the clothes surface, $a$ is the activity coefficient, $d_{m}$ is the moisture content ( $\mathrm{kg} / \mathrm{kg}$ dry air) of the saturated air layer adjacent to the clothes surface, and the $d_{m}$ is the moisture content $(\mathrm{kg} / \mathrm{kg}$ dry air) of dried hot gas at the drum inlet, and $d_{\text {out }}$ is the moisture content $(\mathrm{kg} / \mathrm{kg}$ dry air) of wet air at the moisture outlet.

The mass transfer coefficient $k$ can be determined by the Lewis number:

$$
k=\frac{h}{L e^{2 / 3} c_{p, a}},
$$

where $h$ is the heat transfer coefficient $\left(\mathrm{kW} / \mathrm{m}^{2} \cdot \mathrm{K}\right), c_{p, a}$ is the specific heat of the air $(1.01 \mathrm{~kJ} /(\mathrm{kg} \cdot \mathrm{K}))$, and $L_{e}$ is the Lewis number.

The Lewis number represents the relationship between the temperature and concentration distribution, and it is the ratio of mass and thermal diffusivities [20]. In this paper, $L_{e}=1$ :

$$
L_{e}=\frac{a}{D}
$$

where $a$ is the thermal diffusivity $\left(\mathrm{m}^{2} / \mathrm{s}\right)$, and it represents the ability of the object to become uniform when heated or cooled. Under the same heating condition, the larger the thermal diffusivity is, the smaller the temperature difference is. $D$ is the molecular (or mass) diffusion coefficient $\left(\mathrm{m}^{2} / \mathrm{s}\right)$, and it is defined by Fick's Law [21].

The approximate numerical ranges of heat transfer coefficient on the convective heat transfer surface are listed in Table 3 [20]. The heat transfer between water in the clothes and air is actually carried out in the saturated air layer on the surface of the water. So, it can be treated as forced convection of gas, and the value of $h$ in this paper is set to $100\left(\mathrm{~W} / \mathrm{m}^{2} \cdot \mathrm{K}\right)$. 
TABLE 3: The approximate numerical range of heat transfer coefficient on the convective heat transfer surface.

\begin{tabular}{lc}
\hline Process & $h\left(\mathrm{~W} / \mathrm{m}^{2} \cdot \mathrm{K}\right)$ \\
\hline Natural convection & \\
$\quad$ Air & $1 \sim 10$ \\
$\quad$ Water & $200-1000$ \\
\hline Forced convection & $20-100$ \\
$\quad$ Gas & $500-35000$ \\
High pressure vapor & $1000-1500$ \\
$\quad$ Water & \\
\hline Heat transfer with phase change of water & $2500-3500$ \\
Boiling & $5000-25000$ \\
$\quad$ Vapor condensation & \\
\hline
\end{tabular}

Hence, the mass transfer coefficient in basic case is

$$
k=\frac{0.1 \mathrm{~kW} / \mathrm{m}^{2} \cdot \mathrm{K}}{1^{2 / 3} \times 1.01 \mathrm{~kJ} /(\mathrm{kg} \cdot \mathrm{K})}=0.099 \mathrm{~kg} / \mathrm{m}^{2} \cdot \mathrm{s} .
$$

The activity coefficient can be expressed by the clothes moisture content $(X)[12]$ :

$$
\alpha=1-\frac{\beta \cdot X+\delta}{1+\delta^{\gamma \cdot X}},
$$

where $a$ is the activity coefficient and $\beta, \delta$, and $\gamma$ are constant activity parameters which are related to clothes materials. The cotton clothes: $\beta=18, \delta=2$, and $\gamma=30$. Nylon and artificial clothes: $\beta=25, \delta=65$, and $\gamma=2$. Wool and silk clothes: $\beta=6, \delta=18$, and $\gamma=2$ [12]. $X$ is the moisture content of wet clothes.

According to [22], the format of the initial moisture content rate $\left(X_{0}\right)$ and the final moisture content $\left(X_{f}\right)$ is defined as follows:

$$
X=\frac{m_{w}-1.06 m_{\mathrm{BD}}}{1.06 m_{\mathrm{BD}}},
$$

where $m_{w}$ is mass of wet clothes at certain time $(\mathrm{kg}), m_{\mathrm{BD}}$ is dry mass $(\mathrm{kg})$, and $X$ is moisture content of wet clothes at certain time.

According to the mass conservation law, the increase of moisture content in the drying drum comes from evaporation of clothes' moisture. The air moisture content at the drum's outlet can be calculated by

$$
d_{\text {out }}=d_{\text {in }}+\frac{m_{\text {evap }}}{m_{\text {in }}},
$$

where $d_{\text {in }}$ is the moisture content $(\mathrm{kg} / \mathrm{kg}$ dry air) of dried hot gas at the drum inlet, $d_{\text {out }}$ is moisture content $(\mathrm{kg} / \mathrm{kg}$ dry air) of wet air at the moisture outlet, and $m_{\text {in }}$ is the mass flow rate $(\mathrm{kg} / \mathrm{s})$ of dried hot gas at the drum inlet.

\section{Solution of the Model}

3.1. Numerical Solution of Drying Model. This study uses MATLAB to simulate the heat and mass transfer process of the gas clothes dryer (GCD). The key is to divide the dryer into $\mathrm{N}$ sections, and each section outlet is treated as a node. During time step $(\Delta t)$, the moisture content and temperature of the dried hot gas at each node is calculated in turn and the water evaporation mass is calculated at the same time. The moisture content and temperature of the dried hot gas at the outlet of former node is used as the moisture content and temperature of the latter node, until the clothes moisture content, temperature, and accumulative time at the last node $\mathrm{N}$ are calculated in a time step. Calculate the value of each variable in each time step $(\Delta t)$ until the clothes moisture content reaches the final moisture content. The programming steps are as follows.

Input the initial conditions of drying:

(1) Atmospheric parameters: temperature $\left(T_{a}\right)$, relative humidity $\left(d_{a}\right)$, air velocity $(v)$, and specific heat at constant pressure $\left(c_{p, a}\right)$.

(2) Clothes parameters: dry mass of clothes $\left(m_{\mathrm{BD}}\right)$, initial temperature of clothes $\left(T_{m, o}\right)$, initial wet mass $\left(m_{w, 0}\right)$, final moisture content $\left(X_{f}\right)$, activity constant $(\beta, \gamma, \delta)$, specific heat at constant pressure $\left(c_{p, c}\right)$, and effective heat and mass transfer area $(A)$.

(3) Clothes dryer parameters: drying drum capacity $\left(V_{D}\right)$, initial temperature of drying drum $\left(T_{D, o}\right)$, diameter of moisture outlet $(d)$, and specific heat at constant pressure $\left(c_{p, D}\right)$.

(4) Natural gas parameters: low heating value of each combustible component $H_{l}$, proportion of combustible components, specific heat of each component at constant pressure, measured temperature $\left(T_{g}\right)$, measured pressure $\left(P_{g}\right)$, and measured volume flow rate $\left(V_{g}\right)$.

(5) Drying parameters: section number $(N)$, time step $(\Delta t)$, heat transfer coefficient $(h)$, mass transfer coefficient $(k)$, heat dissipation coefficient at hot gas duct $\left(F_{\mathrm{rfd}}\right)$, and heat dissipation coefficient of drying drum $\left(F_{D}=0.05\right)$.

(i) Calculate $H_{f}$, the enthalpy of the complete combustion exhaust gas.

(ii) Calculate $H_{\text {total }}$, the total enthalpy of the dryer, including the enthalpy of the exhaust gas $\left(H_{f}\right)$, the enthalpy of the mixed air $\left(H_{a, \text { mix }}\right)$, and the preheating of the heated drying drum to air $\left(Q_{D}\right)$, and calculate the moisture content $\left(d_{\text {in }}\right)$ and the temperature of the dried hot gas at the drum inlet $\left(T_{\text {in }}\right)$.

(iii) Then, the time cycle begins and the space cycle is nested in it. According to the mass conservation law, the energy conservation law and the moisture extraction rate (MER) equation, the temperature $\left(T_{\text {out }}^{i}\right)$, moisture content $\left(d_{\text {out }}^{i}\right)$, and the evaporation mass of the dried hot gas $\left(m_{\text {evap }}^{i}\right)$ are calculated in turn at the outlet of each section. Start from $i=1$, recorded as $T_{\text {out }}^{i}, d_{\text {out }}^{i}$ and $m_{\text {evap }}^{i}$.

(iv) The state of the dried hot gas in the former outlet area is used as the state of the dried hot gas in the latter input area, and the same method is used to calculate the dried hot gas temperature $\left(T_{\text {out }}^{i}\right)$, moisture content $\left(d_{\text {out }}^{i}\right)$, and evaporation mass ( $m_{\text {evap }}^{i}$ ) of the $i=2 \sim N$ areas. 
(v) When the Nth section has been calculated, superimpose the water evaporation of the $i=1 \sim N$ section and calculate the total amount of water evaporation within the time step $(\Delta t)$, whilst calculate the average moisture content of clothes $\left(X_{a}\right)$ and compare this value with the input final moisture content $\left(X_{f}\right)$ to determine whether the program ends.

(vi) If the moisture content was not reached the final moisture content $\left(X_{f}\right)$, the program should continue to calculate in the next time step. Calculate the dried hot gas temperature $\left(T_{\text {out }}^{i}\right)$, moisture content $\left(d_{\text {out }}^{i}\right)$, and evaporation mass $\left(m_{\text {evap }}^{i}\right)$ at the outlet of each section, until the moisture content of clothes reaches the final moisture content $\left(X_{f}\right)$.

(vii) In each time step $\Delta t$, output the data of the dried hot gas temperature $\left(T_{\text {out }}^{N}\right)$, moisture content $\left(d_{\text {out }}^{N}\right)$, clothes average moisture content $\left(X_{a}\right)$, and the total time $\left(t_{\text {total }}\right)$.

The simulation algorithm of the GCD's drying process is shown in Figure 2. The program mainly includes a time loop and a nested spatial loop.

3.2. Determination of Time Step. In the actual drying process, the parameters such as temperature and moisture content continuously vary with time. In order to simplify the calculation, the time is discretized to calculate the residence time of dried hot gas in the drum so as to determine the time step:

$$
(\Delta t)_{r}=\frac{V_{D}}{\dot{V}_{a}},
$$

where $(\Delta t)_{r}$ is the residence time of dried hot gas in the drum, $V_{D}$ is the volume of the clothes drying drum $\left(\mathrm{m}^{3}\right)$, and $\dot{V}_{a}$ is the volume flow rate of dried hot gas $\left(\mathrm{m}^{3} / \mathrm{s}\right)$.

The drying process in the time step $(\Delta t)$ is a steady process. In this process, the temperature, relative humidity, clothes temperature, and moisture content are constant; consequently, the value of time step should be much smaller than the residence time of dried hot gas in the drum, $\left(\Delta t<(\Delta t)_{r}\right)$. After calculation $(\Delta t)_{r}=2.09 \mathrm{~s}$, take time step $\Delta t$ as $1 \mathrm{~s}$.

3.3. Analysis of Time Variables. According to the first law of thermodynamics, the drying drum is taken as the study object. In time step $(\Delta t)$, the heat enthalpy at the drum's inlet is equivalent to the sum of heat enthalpy at the drum's outlet, the heat loss, and the heat storage in the drying drum. The stored heat includes heat stored in the clothes, in the clothes moisture, and in the drying drum. The enthalpy at drum's inlet and outlet can be calculated by the mass flow rate, specific heat at constant pressure, and temperature. The enthalpy consists of sensible heat and latent heat. The enthalpy difference between the drum's inlet and outlet consists of sensible heat difference and latent heat difference. The sensible heat difference can be calculated by the mass flow rate, specific heat at constant pressure, and the temperature difference between the drum's inlet and outlet while the latent heat difference can be calculated by the mass of water evaporation between every two-time step $(\Delta t)$. The enthalpy at the drum's inlet is the benchmark of the heat loss in the drying drum. The heat loss coefficient in the drying drum is $F_{D}=0.05$ :

$$
\begin{aligned}
H_{\text {in }} \Delta t-H_{\text {out }} \Delta t & =Q_{\text {stored }} \Delta t+Q_{\text {loss }, D} \Delta t, \\
H_{\text {in }} \Delta t-H_{\text {out }} \Delta t & =m_{\text {in }} c_{p, a}\left(T_{\text {in }}-T_{\text {out }}\right) \Delta t-Q_{\text {evap }} \Delta t, \\
T_{m, \Delta t} & =T_{m, t}+\left[\frac{m_{a} c_{p, a}\left(T_{\text {in }}-T_{\text {out }}\right)-Q_{\text {evap }}-F_{D} H_{\text {in }}}{m_{\mathrm{BD}} c_{p, c l}+1.06 X m_{\mathrm{BD}} c_{p, w}+m_{D} c_{p, D}}\right] \Delta t,
\end{aligned}
$$

where $Q_{\text {stored }}$ is the energy (kJ) stored in the clothes, in the clothes moisture and in the drying drum, $Q_{\text {loss }, D}$ is the heat dissipation $(\mathrm{kJ})$ in the drying drum, $m_{\text {in }}$ is the mass flow rate $(\mathrm{kg} / \mathrm{s})$ of the dried hot gas, $T_{\text {out }}$ is the temperature $\left({ }^{\circ} \mathrm{C}\right)$ of the dried hot gas at the drum's outlet, $Q_{\text {evap }}$ is the heat required for moisture evaporation, $m_{\mathrm{BD}}$ is the dry mass of clothes $(\mathrm{kg}), m_{D}$ is the mass $(\mathrm{kg})$ of the drying drum, $c_{p, \mathrm{cl}}$ is specific heat of clothes at constant pressure $(\mathrm{kJ} / \mathrm{kg} \cdot \mathrm{K}), c_{p, D}$ is specific heat of the drum at constant pressure $(\mathrm{kJ} / \mathrm{kg} \cdot \mathrm{K})$, $c_{p, w}$ is water specific heat at constant pressure $(\mathrm{kJ} / \mathrm{kg} \cdot \mathrm{K}), X$ is moisture content of wet clothes (\%), $T_{m, \Delta t}$ is the clothes average temperature $\left({ }^{\circ} \mathrm{C}\right)$ in moment $t+\Delta t$, and $\Delta t$ is time $\operatorname{step}(\mathrm{s})$.

\subsection{Analysis of Spatial Variables and the Determination of the} Number of Segments. In time step $\Delta t$, the clothes' temperature and the moisture content are constant, and the drying drum is divided into $N$ parts along the moving direction of the dried hot gas. For each section, the temperature at the outlet can be calculated as $[9,10]$

$$
\begin{aligned}
T_{\text {out }}^{i} & =\left[T_{\text {in }}^{i}-T_{m}-(\Delta t)_{\alpha}^{i}\right] \operatorname{Exp}\left(\frac{-h(A / N)}{m_{a} c_{p, a}}\right)+\left[T_{m}+(\Delta t)_{\alpha}^{i}\right], \\
(\Delta t)_{\alpha}^{i} & =\frac{Q_{\text {evap }, N}^{i}+Q_{\text {loss }, D}^{i}}{h A / N}, \\
Q_{\text {evap }, N}^{i} & =m_{\text {evap }}^{i} r_{w} \Delta t,
\end{aligned}
$$

where $T_{\text {out }}^{i}$ is the temperature of dried hot gas $\left({ }^{\circ} \mathrm{C}\right)$ at the No.i section outlet, $T_{\text {in }}^{i}$ is the temperature of dried hot gas $\left({ }^{\circ} \mathrm{C}\right)$ at the No.i section inlet, $\mathrm{Tm}$ is the average temperature of clothes surface $\left({ }^{\circ} \mathrm{C}\right)$ within time step $(\Delta t), Q_{\text {evap }, N}^{i}$ is the latent heat of water evaporation $(\mathrm{kJ})$ at the No.i section within $\Delta t$, $Q_{\text {loss }, D}^{i}$ is the heat dissipation $(\mathrm{KJ})$ in the drying drum at the No.i section within $\Delta t, h$ is the heat transfer coefficient of clothes surface and dried hot gas $\left(\mathrm{kW} / \mathrm{m}^{2} \cdot \mathrm{K}\right), m_{\text {evap }}^{i}$ is the water evaporation rate $(\mathrm{kg} / \mathrm{s})$ at No.i section within $\Delta t$, and $r_{w}$ is the latent heat of water vaporization $(2465.1 \mathrm{~kJ} / \mathrm{kg})$.

The moisture transfers from wet clothes to the dried hot gas, which is carried out under the driving force generating from pressure difference and temperature difference between the air layer adjacent to the wet clothes surface and the 


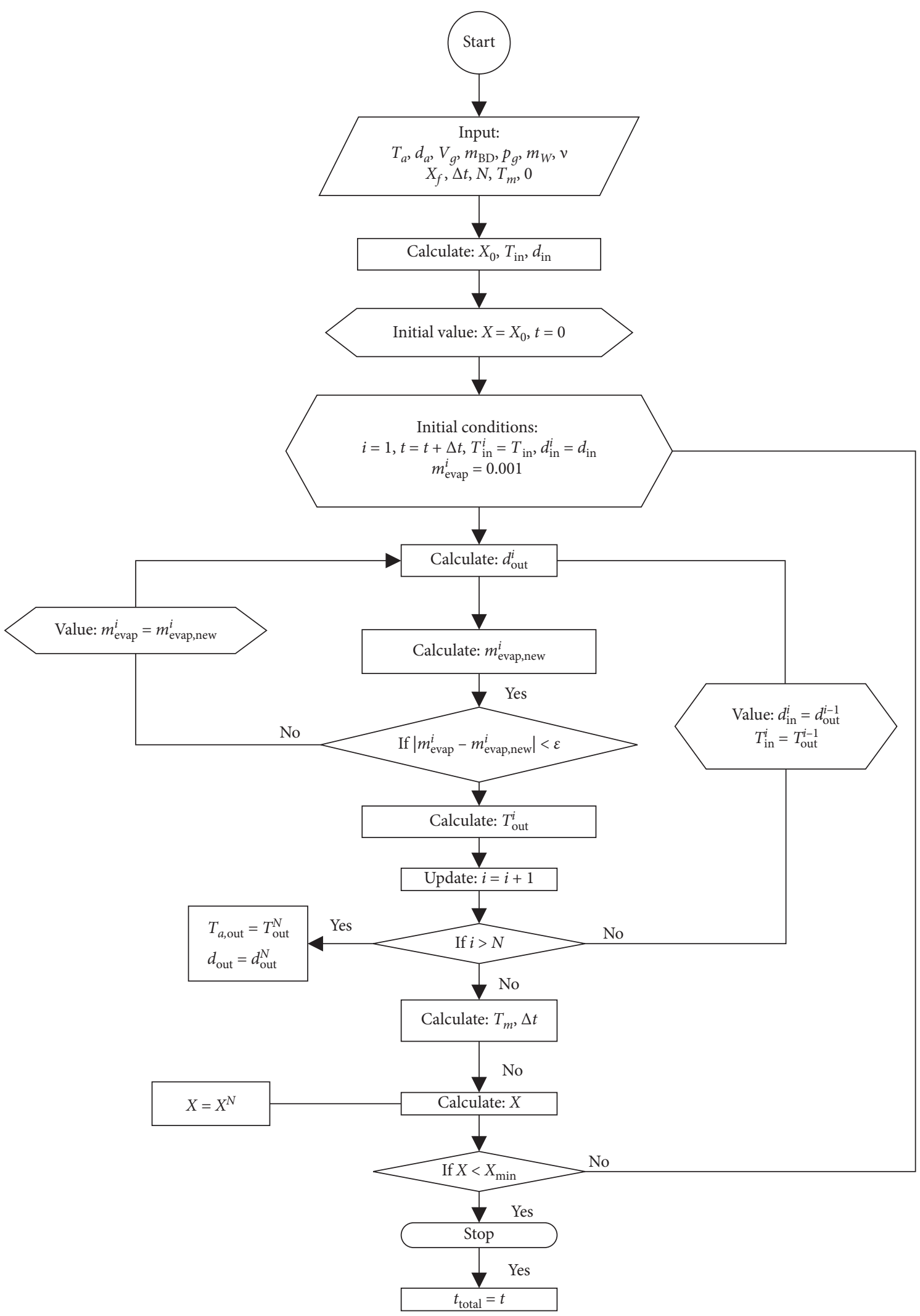

FIgURE 2: Schematic of the algorithm used to simulate the drying process of the GCD. 
dried hot gas. The instantaneous water evaporation rate at No.i section can be calculated as

$$
m_{\text {evap }}^{i}=k A\left[\alpha d_{m}-\frac{d_{\text {in }}^{i}+d_{\text {out }}^{i}}{2}\right],
$$

where $d_{m}$ is the moisture content $(\mathrm{kg} / \mathrm{kg}$ dry air) of the saturated air layer adjacent to the clothes surface, $d_{\text {in }}^{i}$ is the moisture content ( $\mathrm{kg} / \mathrm{kg}$ dry air)of the inlet's dried hot gas at No.i section within $\Delta t$, and $d_{\text {out }}^{i}$ is the moisture content $(\mathrm{kg} /$ $\mathrm{kg}$ dry air) of the outlet's dried hot gas at No.i section within $\Delta t$. Hence, for the No.i section, the moisture content of hot air at the drum's inlet and outlet can be determined as

$$
d_{\mathrm{out}}^{i}=d_{\mathrm{in}}^{i}+\frac{m_{\mathrm{evap}}^{i}}{m_{a}},
$$

The section number $(N)$ of the drum is related to the characteristics and the effective heat transfer area of the clothes. The whole space of the dryer in this paper is divided into 15 parts as

$$
\left(\frac{A q_{c}}{m_{a} c_{p, a} N}\right) \ll 1,
$$

where $q_{c}$ is the convective heat transfer $(\mathrm{kJ})$ between the clothes and dried hot gas.

3.5. Determination of Effective Area. For each piece of clothes, the area is $1 \mathrm{~m}^{2}$ and the mass is $0.5 \mathrm{~kg}$, so the unit mass area of the clothes is $2 \mathrm{~m}^{2} / \mathrm{kg}$ when the clothes is completely unfolded. The volume of drying drum is $102 \mathrm{~L}$. The clothes mass is $1.5 \mathrm{~kg}, 2.5 \mathrm{~kg}, 3.5 \mathrm{~kg}, 4.5 \mathrm{~kg}$, and $6 \mathrm{~kg}$, respectively. Due to the limited space, the clothes will be twined and tangled in the drying drum with rotation of the drum. The effective heat and mass transfer coefficient refer to the unfolding degree of clothes, and it is used to calculate the heat and mass transfer area of the clothes exposed in the air. It varies with time, and there is little research on this subject up to now. Trial and error are a basic methodology in problem solving and knowledge acquisition [23]. Generally speaking, the approach proceeds by posing a sequence of possible candidate solutions and observing their validity. If a proposed candidate solution is found to be valid, then the mission is accomplished [24]. The important features of the approach are its solution orientation (the goal is to find a solution, with no attempt to discover why the solution works) and little knowledge requirement (this approach can proceed where there is little or no knowledge of the subject) [25]. In this paper, the effective heat and mass transfer coefficient was initially assumed as certain values. After completing the simulation and fitting with the experiment data, the validity of the candidate values was judged by the error between the experiment and simulation results. Then, the candidate values were continually adjusted to narrow the error between the experiment and simulation results to a reasonable range. With the method of trial and error, the values of the effective heat and mass transfer coefficient were finally determined to be $45 \%, 40 \%, 35 \%, 30 \%$, and $23 \%$. This assumption is reasonable because the twining effect is intensified with the increase of the clothes mass, and the effective heat and mass transfer area accordingly is

$$
\begin{aligned}
1.5 \mathrm{~kg} \times 2 \mathrm{~m}^{2} / \mathrm{kg} \times 45 \% & =1.35 \mathrm{~m}^{2}, \\
2.5 \mathrm{~kg} \times 2 \mathrm{~m}^{2} / \mathrm{kg} \times 40 \% & =2 \mathrm{~m}^{2}, \\
3.5 \mathrm{~kg} \times 2 \mathrm{~m}^{2} / \mathrm{kg} \times 35 \% & =2.45 \mathrm{~m}^{2}, \\
4.5 \mathrm{~kg} \times 2 \mathrm{~m}^{2} / \mathrm{kg} \times 30 \% & =2.7 \mathrm{~m}^{2}, \\
6 \mathrm{~kg} & \times 2 \mathrm{~m}^{2} / \mathrm{kg} \times 23 \%=2.76 \mathrm{~m}^{2} .
\end{aligned}
$$

\section{Verification and Analysis of the Drying Model of the GCD}

This paper verifies the model's validity by studying the variation regularities of temperature and clothes moisture content at the drying drum's outlet over time. The dry masses of clothes are $1.5 \mathrm{~kg}, 3.5 \mathrm{~kg}$, and $6 \mathrm{~kg}$, respectively, which represents the small, medium, and large conditions. If the simulation results are highly consistent with the experimental results in the three cases, it can be concluded that the model can be applied to all cases within drying capacity.

\subsection{Verification Experiment}

4.1.1. Experiment Devices, Instruments, and Experiment Conditions. The experiment devices, instruments, and experiment conditions are shown in Figure 3.

4.1.2. Experiment Content. The experiment mainly tested the variation regularities of temperature and clothes moisture content at the drying drum outlet with time when the dry masses of clothes were $1.5 \mathrm{~kg}, 3.5 \mathrm{~kg}$, and $6 \mathrm{~kg}$, respectively. The experiment under the same condition was carried out twice. First, the dryer kept running continuously and we used the temperature and humidity recorder to collect the variation data of temperature and humidity at the CD's outlet. Next, the dryer kept running intermittently every 2 min and we recorded the variation data. The mass of wet clothes is difficult to accurately measure due to the acceleration. Therefore, we measured the mass of wet clothes using the discontinuous method. The clothes are taken out of the halted dryer every $2 \mathrm{~min}$ until the clothes reach the required final moisture content.

According to Article 7.3.3 of GB/T 20292-2006 “Tumble dryers for household use-Methods for measuring the performance," clothes dry mass refers to the mass after being treated by a very dry method. The equilibrium moisture content of the clothes is related to environmental temperature and relative humidity. Under the convection of air, the moisture in the clothes will exchange with the moisture in the atmosphere until the moisture in the environment reaches equilibrium. Due to the complex and uncontrollable situation when the clothes are exposed to the air and keep absorbing moisture from the surrounding air, this treatment aims to adjust the clothes mass before the experiment to ensure that the clothes are under the same condition. In this 


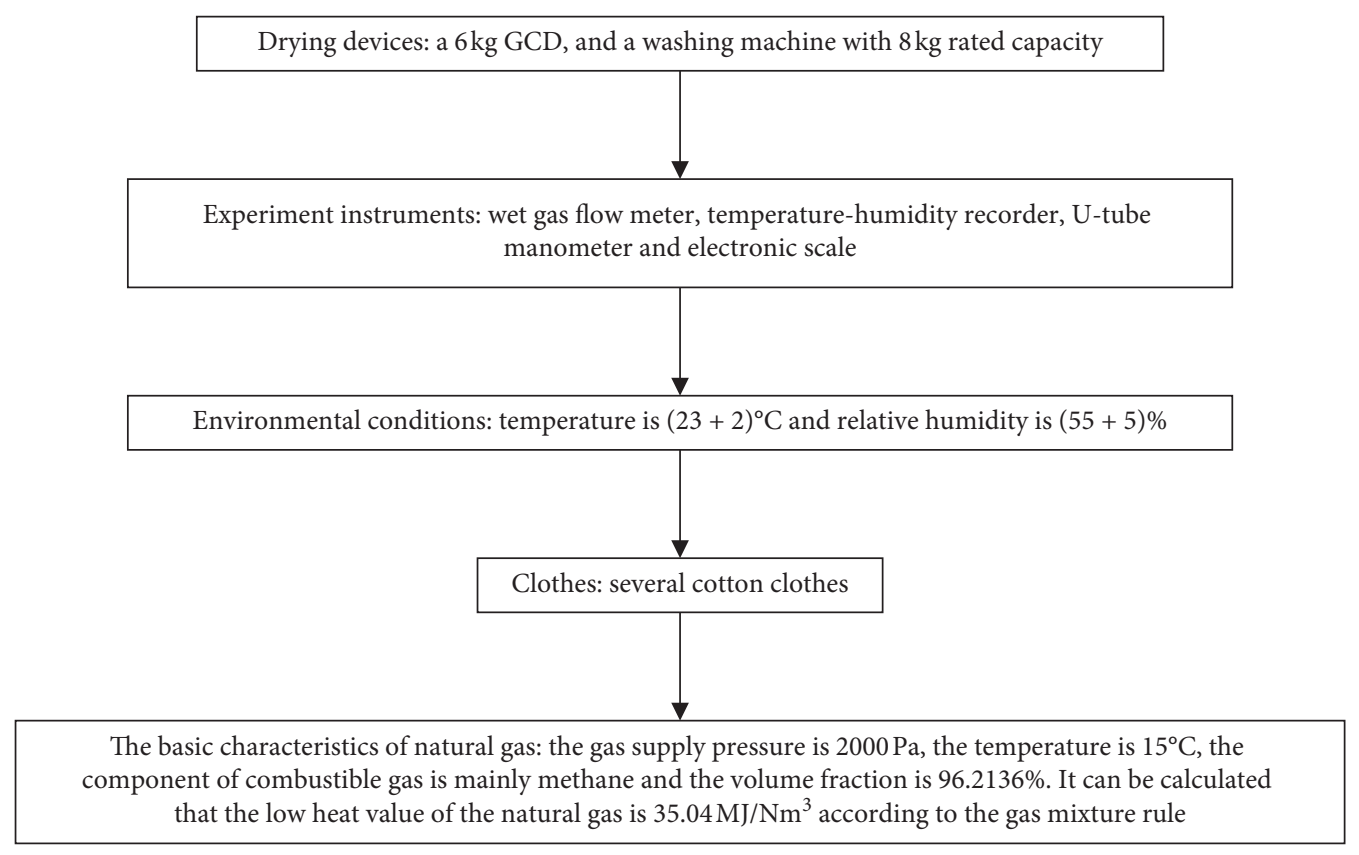

FIGURE 3: The experiment devices, instruments, and experiment conditions.

work, the clothes are treated by the very dry method to obtain the clothes dry mass under the same air condition.

The clothes are disposed by the method in Appendix C in [22], and the mass is the dry mass of clothes. The balanced moisture content of the clothes is concerned with the ambient temperature and relative humidity. Under the convection of the air, the water contained in clothes exchanges with the water in the environment until it reaches equilibrium. The clothes keep absorbing moisture in the air, and this process is complex and uncontrollable, while this treatment ensures the mass of clothes is same before the experiment.

According to Appendix C of [22], the tumble dryer used to estimate that the very dry mass should meet the requirements: when drying the clothes with the very dry method and taking $\mathrm{kg}$ as the unit of the dryer's rated capacity, the mass of single fabric should not exceed $1 \mathrm{~kg}$ per $20 \mathrm{~L}$ tumble volume. In this experiment, the dimensions of the drying drum are as follows: the diameter is $59.5 \mathrm{~cm}$, the height is $37 \mathrm{~cm}$, and the volume is $102 \mathrm{~L}$. The maximal rated capacity is $6 \mathrm{~kg}$, and the result is valid when the mass of single clothes is no more than $5 \mathrm{~kg}$. Therefore, the drying process was carried out twice and the drying capacity was $3.5 \mathrm{~kg}$ and $2.5 \mathrm{~kg}$, respectively. Put the dry clothes into the dryer, run the dryer for $30 \mathrm{~min}$ with the maximum power, and stir the clothes manually every $10 \mathrm{~min}$ to ensure that the clothes do not twine. Then, it continues to dry. The process, including the time to open and close the dryer's door, should be completed within $30 \mathrm{~s}$. After $30 \mathrm{~min}$, stop running the dryer, take out the clothes, and weigh the clothes as quickly as possible before they cool and absorb moisture from the air. If its difference with initial mass is less than $1 \%$, the mass is called the dry mass of clothes $\left(m_{\mathrm{BD}}\right)$ and the adjustment mass $\left(m_{t}\right)$ is 1.06 times of $m_{\mathrm{BD}}$, that is, $m_{t}=1.06 m_{\mathrm{BD}}$. The definitions of initial moisture of clothes $\left(X_{o}\right)$ and final moisture of clothes $\left(X_{f}\right)$ are based on the adjustment mass $\left(m_{t}\right)$.

The initial moisture of clothes $\left(X_{o}\right)$ refers to the moisture content of the clothes that is dehydrated by washing machine and is not dried by the dryer while the final moisture of clothes $\left(X_{f}\right)$ refers to the moisture content which meets drying requirements after drying. Wet mass refers to the mass of wet clothes which is not completely dried after dehydration. In this paper, $X_{o}$ is $60 \%$. If the wet mass after dehydration is higher than $60 \%$ of $X_{o}$, it should be dehydrated again using the washing machine. If the wet mass is lower than $60 \%$ of $\left(X_{o}\right)$, the sprayer should be used to humidify. Repeat the experiment twice for each drying method and drying mass, and take the average of two experiment results to guarantee the reliability. According to [22], initial moisture of clothes $\left(X_{o}\right)$ and final moisture of clothes $\left(X_{f}\right)$ are defined as

$$
X_{o}=\frac{m_{o}-1.06 m_{\mathrm{BD}}}{1.06 m_{\mathrm{BD}}},
$$

where $X_{o}$ is the initial moisture of clothes (\%), $m_{o}$ is the clothes mass $(\mathrm{kg})$ after dehydration without drying, and $m_{\mathrm{BD}}$ is the dry mass of clothes $(\mathrm{kg})$.

$$
X_{f}=\frac{m_{f}-1.06 m_{\mathrm{BD}}}{1.06 m_{\mathrm{BD}}} \text {, }
$$

where $X_{f}$ is the final moisture of clothes (\%) and $m_{f}$ is the clothes mass (kg) after drying. According to [22], the final moisture of clothes should not exceed 3\%.

The advantages of the methodology above to estimate clothes moisture content are

(1) It is relative authentic. The methodology comes from the Chinese National Standard [22], which was issued by the China National Light Industry 
Federation and drafted by the China Home Appliances Research Institute.

(2) It is practicable, the moisture content of clothes can be calculated by measuring the clothes mass after dehydration without drying, the dry mass of clothes, and the clothes mass after drying.

The disadvantage of this method is that it is based on engineers' experiences or a large number of experiments by the appliance manufacturers, other than theoretical derivation.

4.1.3. Experimental Procedure. The experimental procedure of the drying drum's outlet temperature measuring is summarized in Figure 4.

The experimental procedure of clothes moisture content measuring is summarized in Figure 5. The wet clothes are weighed every $2 \mathrm{~min}$ using an electronic scale with the precision of $1 \mathrm{~g}$ :

\subsection{Effectiveness Analysis of the Drying Model of the GCD}

4.2.1. Comparative Analysis of Simulation and Experiment Results concerning Temperature at the Drying Drum's Outlet. As shown in Figure 6, the simulation results and experiment results have high consistency when the dry mass of clothes is $1.5 \mathrm{~kg}, 3.5 \mathrm{~kg}$, and $6 \mathrm{~kg}$, respectively. The drying regularities have the following characteristics: with the drying process, the temperature at the drying drum's outlet increases first, then approximates the constant temperature, and finally increases again. This regularity is coincident with the temperature rise period, constant-rate drying period, and falling-rate drying period in theory. In the simulation, the dryer enters next periods earlier than in the experiment. This is because the flow rate of dried hot gas is a constant of $10 \mathrm{~m} / \mathrm{s}$ in the simulated process. But in fact, the flow rate of the dried hot gas in the temperature-rise period is a variable with the maximum of $14 \mathrm{~m} / \mathrm{s}$. As the drying process progresses, the flow rate of dried hot gas gradually decreases to a constant about $10 \mathrm{~m} / \mathrm{s}$. The air temperature of the simulated process is higher, and the dryer enters the constant-rate drying period from temperature-rise period earlier, and thus enters the falling-rate drying period earlier.

With the increase of the dry mass of clothes $\left(m_{\mathrm{BD}}\right)$, the temperature difference at the constant-rate drying period diminishes gradually. When $m_{\mathrm{BD}}$ is $1.5 \mathrm{~kg}, 3.5 \mathrm{~kg}$, and $6 \mathrm{~kg}$, the maximum temperature difference was $6^{\circ} \mathrm{C}, 3^{\circ} \mathrm{C}$, and $1^{\circ} \mathrm{C}$, correspondingly. It is obvious that the simulation result is more accurate when $m_{\mathrm{BD}}$ is large enough.

At the falling-rate drying period, there is a similar characteristic when $m_{\mathrm{BD}}$ is $1.5 \mathrm{~kg}, 3.5 \mathrm{~kg}$, or $6 \mathrm{~kg}$. The temperature at the drying drum's outlet in the simulation are obviously higher than the experiment data, and the simulated results increase faster with the drying process. This is because the clothes movement in the drying drum, including the axial movement along the direction of dried hot gas and the approximate circular movement around the axis, has not been taken into consideration in the simulated process.
During the constant-rate drying period, the clothes surface is full of free water. The drying in this period exhibits the evaporation on ordinary water surface; therefore, the clothes movement has little effect on the constant-rate drying period. During the falling-rate drying period, the clothes surface appears partially dry, and the decrease of clothes moisture weakens the twining effect on the clothes. Moreover, the clothes motion exposes the wet part of clothes to the dried hot gas. At the same time, the clothes move from the rear to the inlet of the drying drum, and more heat is used to evaporate the water, making temperature at outlet rise gradually. Since the relative position is constant, after reaching the dry mass, the clothes near the drum's inlet will not be dried further and the heat used to dry decreases, so the upward trend of temperature at the drum's outlet is obviously greater than that of experiment results.

\subsubsection{Comparative Analysis of Clothes Moisture Content's} Simulation and Experiment Results. To further verify the validity of the model, the simulation and experiment results concerning variation regularity of clothes moisture content are compared and analyzed when the dry masses of clothes are $1.5 \mathrm{~kg}, 3.5 \mathrm{~kg}$, and $6 \mathrm{~kg}$. As shown in Figure 7, the simulation results are highly coincident with the experimental results and the relative deviation is less than 3\%. The variation regularity of clothes moisture content with time is nonlinear. During the temperature-rise period, the evaporation rate is low because the dried hot gas is mainly used to raise the temperature of the drying drum and clothes and the little heat is used for evaporation. As a result, the slope about variation regularity of clothes moisture content with time is small. During the constant-rate drying period, the moisture extraction rate (MER) is constant. With the evaporation of surface water, there appears partially dry on the clothes surface, and the drying resistance becomes larger. The moisture extraction rate (MER) continues to decline, so it enters the falling-rate drying period [26].

When the dry mass of clothes is $1.5 \mathrm{~kg}$, the clothes occupy little space in the drying drum, and the shielding effect on the dried hot gas is relatively small; therefore, heat used to evaporate water is correspondingly small. During the temperature-rise period and constant-rate drying period, a large amount of the heat is drained out of the drying drum, so the moisture extraction rate (MER) in simulation is faster than the actual MER, and the clothes moisture content in simulation is lower than the experimental result. When the dry mass of clothes is $3.5 \mathrm{~kg}$ and $6 \mathrm{~kg}$, the contact time of the dried hot gas and the clothes can be extended because the clothes occupy more space in the drying drum, so compared with the condition that the dry mass of clothes is $1.5 \mathrm{~kg}$, the clothes moisture content in simulation has higher consistency with the experimental clothes moisture content. After entering the falling-rate drying period, the moisture extraction rate (MER) in simulation is lower than the experimental MER, since the movement of the clothes is not considered in the simulation. The clothes enter the fallingrate drying period at $900 \mathrm{~s}(15 \mathrm{~min}), 1620 \mathrm{~s}(27 \mathrm{~min})$, and $2600 \mathrm{~s}(43 \mathrm{~min})$ of the drying process when the dry masses of 


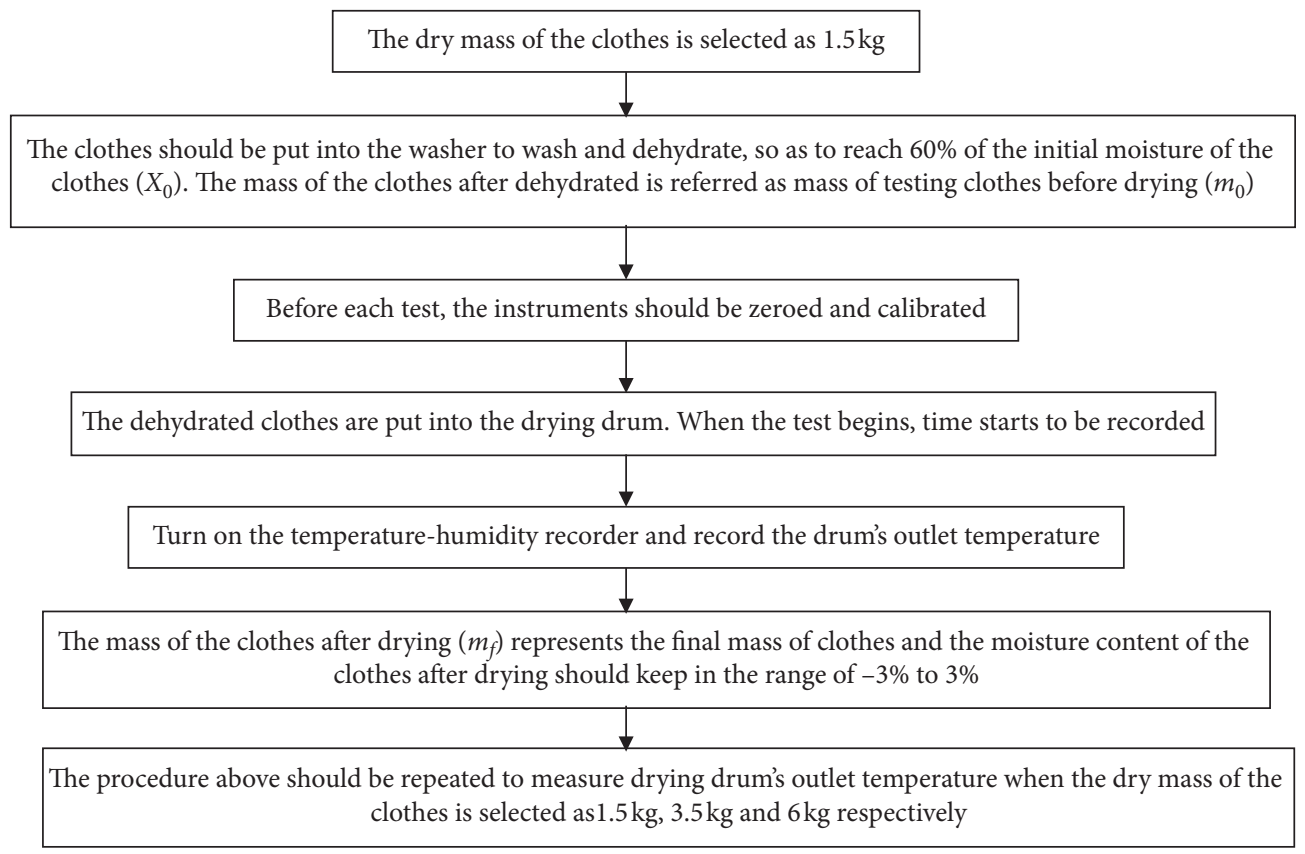

FIGURE 4: The experimental procedure of the drying drum's outlet temperature measuring.

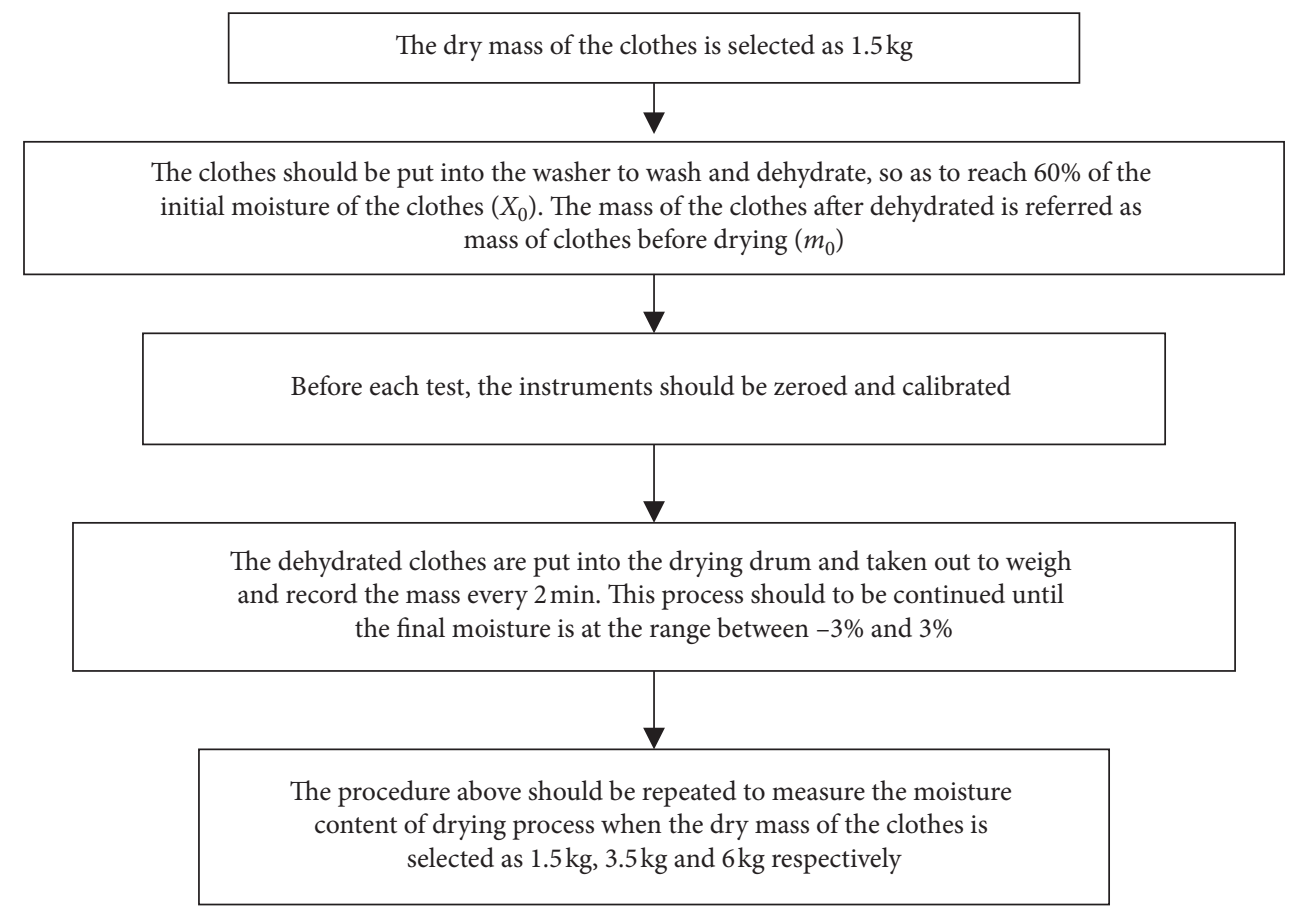

FIGURE 5: The experimental procedure of clothes moisture content measuring.

clothes are $1.5 \mathrm{~kg}, 3.5 \mathrm{~kg}$ and $6 \mathrm{~kg}$, respectively. Both the experimental results and simulation results have this regularity.

Through the comparison and analysis of the simulation and experimental results of temperature at the drying drum's outlet and clothes moisture content, it can be concluded that the model has a high degree of reliability, and the simulation results are more accurate when the dry mass of clothes is large enough. Therefore, the model can be used to further predict regularity of the drying process and provide a theoretical basis for the design and optimization of the GCD.

\section{Research on Optimization of Drying Parameters of the GCD}

The model of the CD can be used to study the performance of the dryer, and it can provide a theoretical basis for 


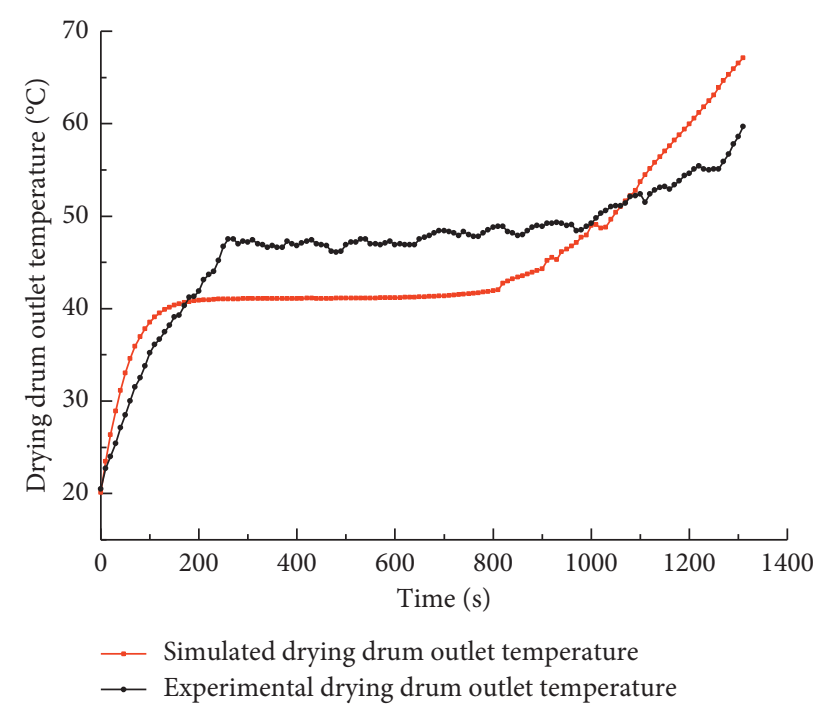

(a)

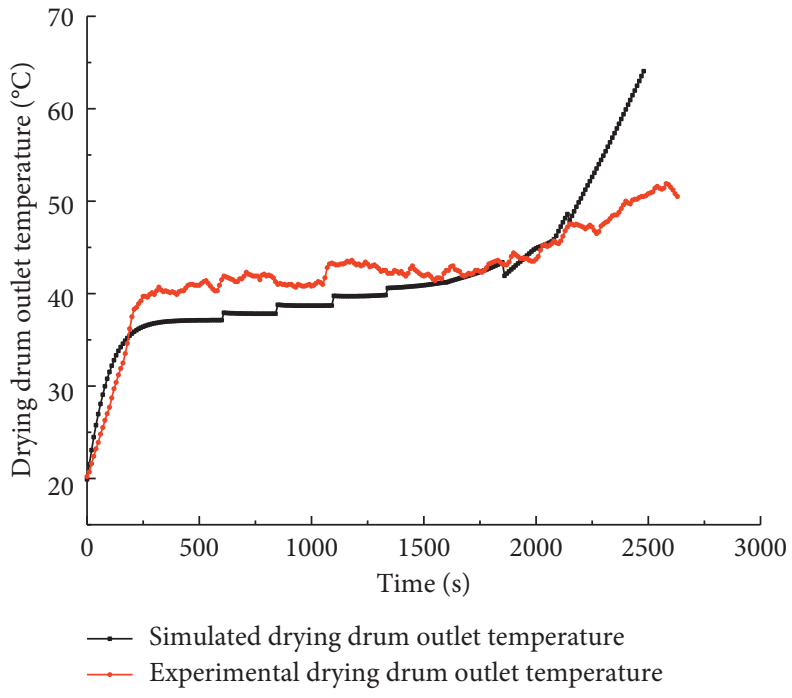

(b)

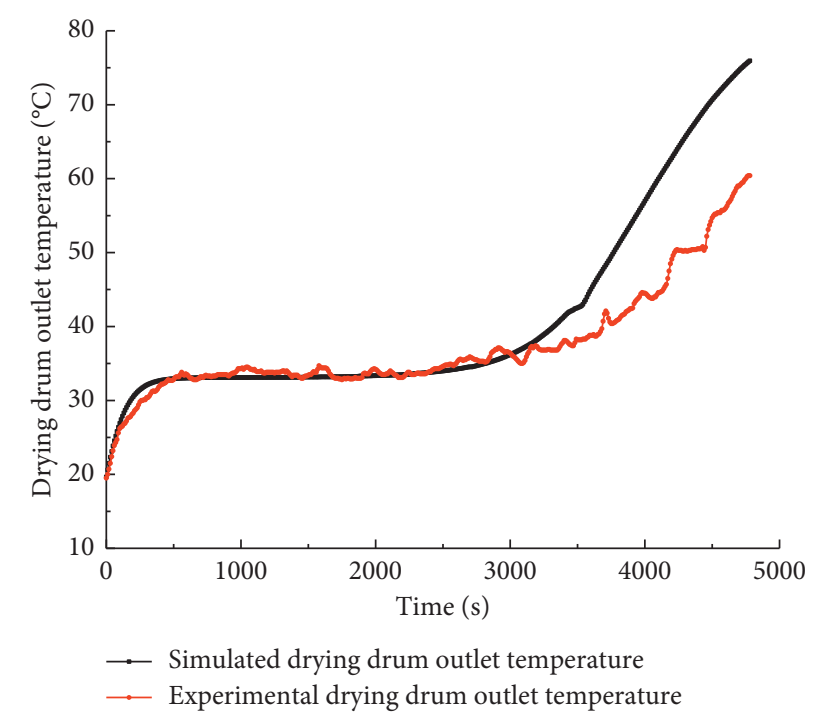

(c)

Figure 6: Comparison of temperature at the drying drum's outlet in experiment and simulation. (a) $1.5 \mathrm{~kg}$. (b) $3.5 \mathrm{~kg}$. (c) $6 \mathrm{~kg}$.

improvement of the dryer. When ambient temperature is $20^{\circ} \mathrm{C}$, environmental relative humidity is $60 \%$, dry mass of clothes is $3.5 \mathrm{~kg}$, gas pressure is $2000 \mathrm{~Pa}$, and gas flow is $390 \mathrm{~L} / \mathrm{h}$ at $15^{\circ} \mathrm{C}$, we studied the sensitivity of dryer performance to parameters such as environmental temperature, ambient humidity, dry mass of clothes, and gas flow rate and also discussed the influence of textile type and moisture extraction rate (MER) of clothes on dryer performance.

5.1. Sensitivity Analysis. The drying time and specific moisture extraction rate (SMER) are used to analyze the sensitivity of GCD performance to parameters. The sensitivity analysis of the drying time to the variation of parameters is shown in Figure 8. The main factors affecting the GCD's drying time are the gas flow and the dry mass of clothes. The GCD's drying time decreases with the increase of gas flow and the decrease of dry mass of clothes. The sensitivity analysis of the SMER to each parameter is shown in Figure 9. The main factors affecting the GCD's SMER are the ambient temperature and relative humidity. The SMER decreases with the increase of the ambient temperature and the decrease of the relative humidity. It is worth noting that this conclusion holds when the benchmark percentage is in the range between 0.6 and 1.4 .

5.2. Textile Type. The effect of textile type on GCD's performance is shown in Table 4. The environmental parameters are as follows: the ambient temperature is $20^{\circ} \mathrm{C}$, the environmental relative humidity is $60 \%$, the gas pressure is $2000 \mathrm{~Pa}$, the gas temperature is $15^{\circ} \mathrm{C}$, and the gas flow rate is $390 \mathrm{~L} / \mathrm{h}$. The experiment clothes are nylon, pure cotton, and wool, respectively, and the clothes are dried from initial moisture content of $60 \%$ to $3 \%$. And the drying time, moisture extraction rate (MER), SMER, and energy 


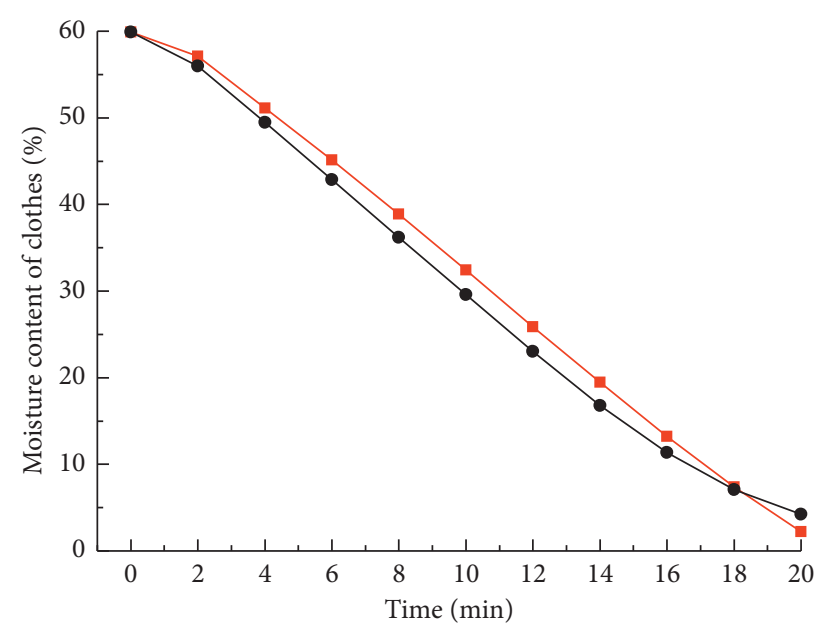

Experimental load water content Simulated load water content

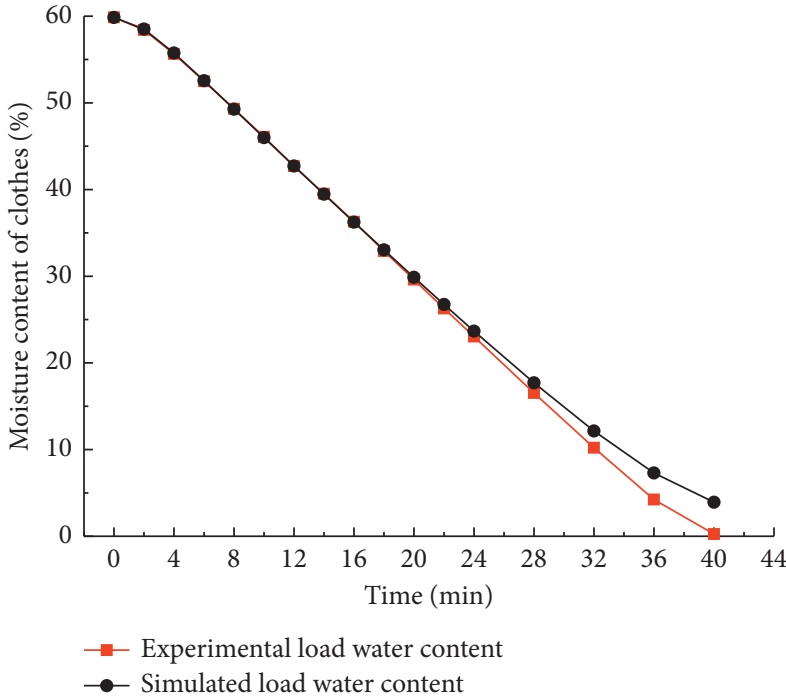

(b)

(a)

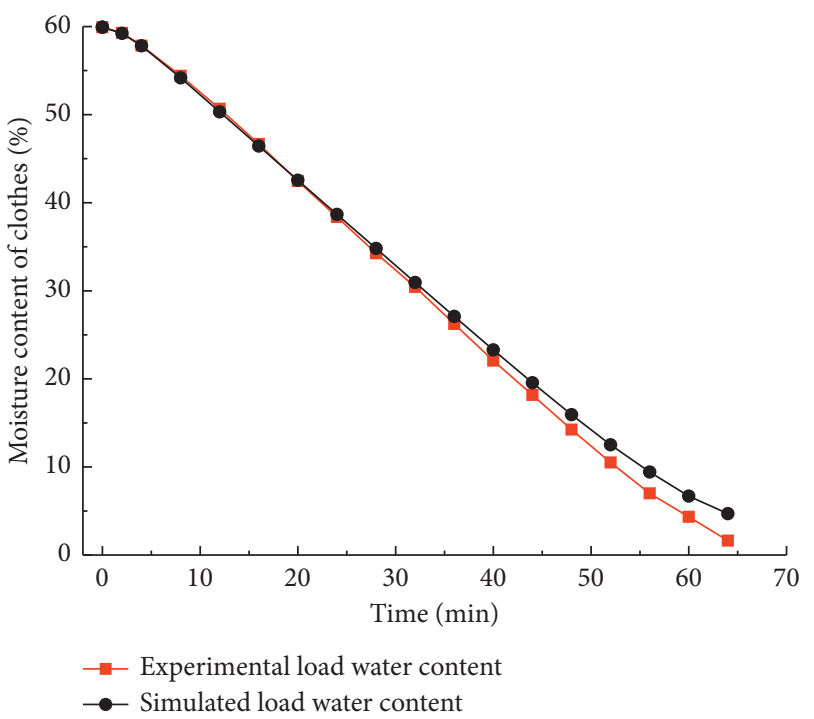

(c)

Figure 7: Comparison of experiment and simulation for moisture content of clothes. (a) $1.5 \mathrm{~kg}$. (b) $3.5 \mathrm{~kg}$. (c) $6 \mathrm{~kg}$.

efficiency are used to evaluate the effect of the textile type on the dryer's performance. The nylon clothes have the fastest moisture extraction rate (MER), followed by the pure cotton clothes and the wool clothes. However, nylon clothes have the least SMER, followed by the pure cotton clothes and the wool clothes. Additionally, nylon clothes have the highest energy efficiency, followed by the pure cotton clothes and the wool clothes. These results are mainly related to the fiber type of the clothes. During the temperature-rise period and constant-rate drying period, the drying process is not affected by the textile type. But during the falling-rate drying period, the textile type begins to affect the drying process. The textile type decides the activity coefficient such as moisture diffusivity, thus affecting the drying process. Ling [27] researched on different fiber types and yarn structures and found that the moisture extraction rate (MER) during the falling-rate drying period is decided by moisture diffusivity which is affected by the fiber type and yarn structure. The moisture diffusivity of wool and pure cotton is small, which leads to longer drying time and larger drying energy consumption.

5.3. Moisture Extraction Rate (MER) of Clothes. The environmental parameters are as follows: the ambient temperature is $20^{\circ} \mathrm{C}$, the relative humidity is $60 \%$, the gas pressure is $2000 \mathrm{~Pa}$, the gas temperature is $15^{\circ} \mathrm{C}$, the clothes are cotton, and the gas flow rate is $390 \mathrm{~L} / \mathrm{h}$. The clothes are dried from initial moisture content of $60 \%$ to final moisture content of $0.5 \%, 5 \%, 10 \%, 15 \%, 20 \%, 25 \%$, and $30 \%$ in turn. The drying time, moisture extraction rate (MER), SMER, and energy efficiency are used to evaluate the effect of different MERs on CD's performance. The effect of the MER on GCD's performance is shown in Table 5 and Figure 10. The results 


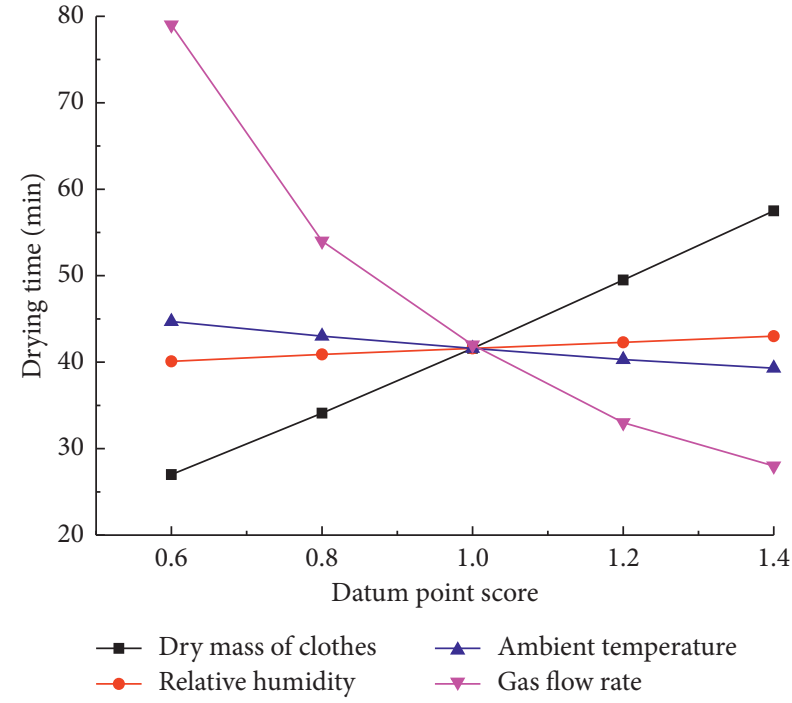

Figure 8: The sensitivity of drying time to the changes in parameters.

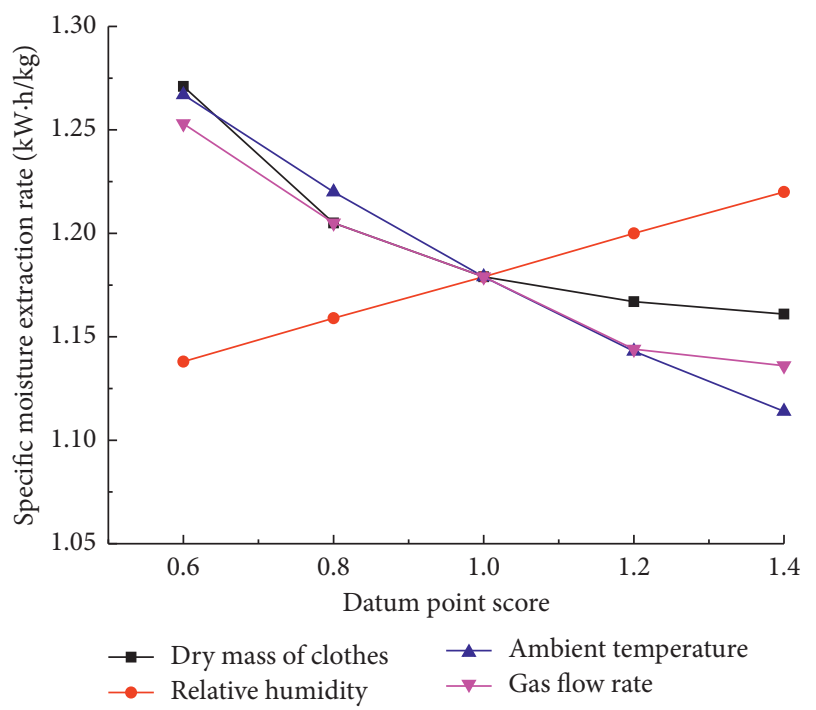

FIGURE 9: The sensitivity of the specific moisture extraction rate (SMER) to the changes in parameters.

TABLE 4: Effect of textile type on performance of the GCD.

\begin{tabular}{lccc}
\hline Type & Nylon & Cotton & Wool \\
\hline Drying time (min) & 38 & 41.5 & 43 \\
Moisture extraction rate $(\mathrm{kg} / \mathrm{h})$ & 3.353 & 3.079 & 2.988 \\
Specific moisture extraction rate (SMER) & 1.078 & 1.174 & 1.210 \\
$\left(\mathrm{~kW} \cdot \mathrm{h} \cdot \mathrm{kg}^{-1}\right)$ & 63.5 & 58.3 & 56.6 \\
\hline Energy efficiency (\%)
\end{tabular}

indicate that the higher the MER (i.e., the lower the final moisture content), the longer the drying time and the larger the drying energy consumption. This result is mainly related to the mass of evaporated water from the clothes. The results in Figure 10 imply that the moisture extraction rate (MER) and SMER are not affected by dehumidification
TABLE 5: Effect of moisture extraction rate (MER) of clothes on performance of the GCD.

\begin{tabular}{lccccccc}
\hline $\begin{array}{l}\text { Type (final rate } \\
\text { of moisture } \\
\text { content) (\%) }\end{array}$ & 0.5 & 5.0 & 10.0 & 15.0 & 20.0 & 25.0 & 30.0 \\
\hline $\begin{array}{l}\text { Drying time } \\
\text { (min) }\end{array}$ & 52.6 & 38.6 & 33.7 & 29.9 & 26.5 & 23.2 & 20.0 \\
$\begin{array}{l}\text { Initial mass (kg) } \\
5.973\end{array}$ & 5.973 & 5.973 & 5.973 & 5.973 & 5.973 & 5.973 \\
$\begin{array}{l}\text { Final mass (kg) } \\
\text { Moisture } \\
\text { extraction rate } \\
\text { (MER) (kg/h) }\end{array}$ & 2.535 & 3.923 & 4.110 & 4.297 & 4.484 & 4.671 & 4.857 \\
$\begin{array}{l}\text { SMER (kW·h/ } \\
\text { kg) }\end{array}$ & 1.427 & 1.134 & 1.089 & 1.075 & 1.071 & 1.072 & 1.078 \\
$\begin{array}{l}\text { Energy } \\
\text { efficiency (\%) }\end{array}$ & 48.0 & 60.4 & 62.9 & 63.7 & 64.0 & 63.9 & 63.5 \\
\hline
\end{tabular}

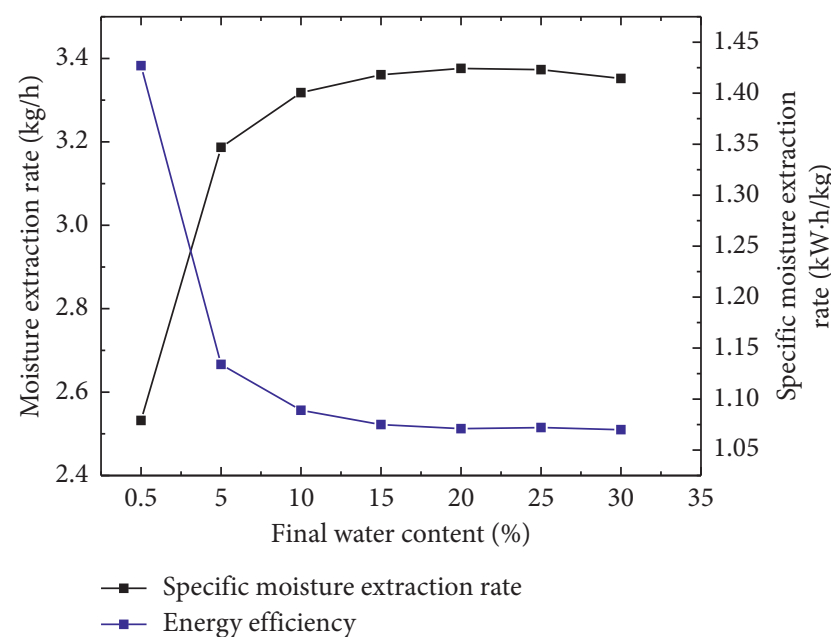

Figure 10: Effect of MER of clothes on performance of the GCD.

mass when the final moisture content is in the range from $10 \%$ to $30 \%$ (at constant-rate drying period). When the final moisture content declines to lower than $10 \%$, the drying time begins to increase dramatically, the SMER rises rapidly, and the energy efficiency declines sharply. The lower the final moisture content of clothes, the greater the trend of decrease. It is obvious that the clothes start to enter the falling-rate drying period when moisture content is $10 \%$. Under the premise of ensuring the drying requirements, it is evident that reducing the operating time in the falling-rate drying period can effectively improve energy efficiency and increase moisture extraction rate (MER). At present, the automatic timing control mode of the GCD is based on the clothes temperature detection device in the drum to determine the drying time, thus the clothes are often overdrying. It is suggested that the setting end temperature should properly decrease when designing the GCD so as to ensure that the clothes meets drying requirements while reducing energy consumption and drying time. It is suggested that when using the GCD, users should remove clothes from the dryer in time to avoid excessive drying. 


\section{Conclusion}

This paper uses the modular modeling method to establish a drying model for natural gas in the combustion chamber, air and exhaust gas in the hot gas duct, and designs the experiment to verify the validity of the model. MATLAB software is used to study variation regularity of temperature at the drum's outlet and clothes moisture content with time. By comparing the variation curves when dry mass of clothes is $1.5 \mathrm{~kg}, 3.5 \mathrm{~kg}$, and $6 \mathrm{~kg}$, respectively, it can be found that the simulation results and the experiment results have high consistency, and the validity of the model is verified.

Through the sensitivity analysis, it can be found that the main factors affecting drying time of the GCD are the gas flow and the dry mass of clothes. The main factors affecting the specific moisture extraction rate (SMER) of the gas dryer are the environmental temperature and relative humidity. Moreover, by using this drying model, the effect of textile type and clothes' moisture extraction rate (MER) on energy efficiency and MER is predicted. The results show that the nylon clothes have the fastest MER and the smallest SMER. Through the study of the clothes moisture content, it is found that under the premise of ensuring the drying requirement, reducing operating time in the fallingrate drying period can improve drying rate and energy efficiency.

\section{Data Availability}

The Outlet Temperature and Humidity Effectiveness data used to support the findings of this study are included within the supplementary information files.

\section{Conflicts of Interest}

The authors declare that there are no conflicts of interest regarding the publication of this paper.

\section{Acknowledgments}

This work was supported by the National Key Project of Research and Development Program of the 13th Five-Year (grant no. 2018YFD1100704). The authors deeply appreciate this support.

\section{Supplementary Materials}

The submitted supplementary material "Verification of Outlet Temperature and Humidity Effectiveness" is the raw experimental data generated by GSP-6 temperature and humidity Data Logger to verify the validity of the drying drum outlet temperature. The supplementary material "Experiment vs Simulation Data" is used to support "Effectiveness analysis of the drying model of gas clothes dryers." (Supplementary Materials)

\section{References}

[1] X.-Q. Sang, Clothes Dryer Market Has Great Potential, China Consumer News, Beijing China, 2008.

[2] P. Bansal, K. Sharma, and S. Islam, "Thermal analysis of a new concept in a household clothes tumbler dryer," Applied Energy, vol. 87, no. 5, pp. 1562-1571, 2010.
[3] T. Yi, J. C. Dye, M. E. Shircliff, and F. Ashrafzadeh, "A new physics-based drying model of thin clothes in air-vented clothes dryers," IEEE/ASME Transactions on Mechatronics, vol. 21, no. 2, pp. 872-878, 2016.

[4] D. Tranxuan and J. Deans, "A computer simulation of a domestic tumbler drier," Transport Phenomena Heat Mass Transfer, vol. 2, pp. 1026-1036, 1992.

[5] P. Nordon and H. G. David, "Coupled diffusion of moisture and heat in hydroscopic textile materials," International Journal of Heat and Mass Transfer, vol. 10, no. 7, pp. 853-866, 1967.

[6] A. J. Lambert, F. P. M. Spruit, and J. Claus, "Modelling as a tool for evaluating the effects of energy-saving measures. Case study: a tumbler drier," Applied Energy, vol. 38, no. 1, pp. 33-47, 1991.

[7] J. Deans, "The modelling of a domestic tumbler dryer," Applied Thermal Engineering, vol. 21, no. 9, pp. 977-990, 2001.

[8] A. M. Bassily and G. M. Colver, "Performance analysis of an electric clothes dryer," Drying Technology, vol. 21, no. 3, pp. 499-524, 2003.

[9] A. M. Bassily and G. M. Colver, "Correlation of the area-mass transfer coefficient inside the drum of a clothes dryer," Drying Technology, vol. 21, no. 5, pp. 919-944, 2003.

[10] T. K. Sherwood, "The drying of solids-I," Industrial \& Engineering Chemistry, vol. 21, no. 1, pp. 12-16, 1929.

[11] T. K. Sherwood, "The drying of solids-II," Industrial \& Engineering Chemistry, vol. 21, no. 10, pp. 976-980, 1929.

[12] V. Yadav and C. G. Moon, "Modelling and experimentation for the fabric-drying process in domestic dryers," Applied Energy, vol. 85, no. 5, pp. 404-419, 2008.

[13] S. Delshad and G. Thomas, "State space realization of wood drying process: modelling, simulation, and evaluation in reality," in Proceedings of the IEEE International Conference on Systems, Man, and Cybernetics, pp. 4731-4736, Manchester, UK, October 2013.

[14] A. B. Ng and S. Deng, "A new termination control method for a clothes drying process in a clothes dryer," Applied Energy, vol. 85, no. 9, pp. 818-829, 2008.

[15] K. R. Gluesenkamp, P. Boudreaux, V. K. Patel, D. Goodman, and B. Shen, "An efficient correlation for heat and mass transfer effectiveness in tumble-type clothes dryer drums," Energy, vol. 172, pp. 1225-1242, 2019.

[16] A. V. Luikov, V. A. Sheiman, P. S. Kuts, and L. S. Slobodkin, "An approximate method of calculating the kinetics of the drying process," Journal of Engineering Physics and Thermophysics, vol. 13, no. 5, pp. 725-734, 1967.

[17] J. E. Braun, P. K. Bansal, and E. A. Groll, "Energy efficiency analysis of air cycle heat pump dryers," International Journal of Refrigeration, vol. 25, pp. 954-965, 2002.

[18] Tongji University, Chongqing University, and Harbin Institute of Technology, Beijing Institute of Architectural Engineering. Gas Combustion and Application, China Building Industry Press, Beijing, China, 2011.

[19] G.-Q. Liu, L.-X. Ma, and S.-g. Xiang, Chemical and Chemical Industry Property Parameter Manual, Chemical and Chemical Industry Press, Beijing, China, 2013.

[20] S.-M. Yang and W.-Q. Tao, Heat Transfer, Higher Education Press, Beijing, China, 4th edition, 2006.

[21] E. L. Cussler, Diffusion Mass Transfer in Fluid System, Cambridge University Press, Cambridge, UK, 2nd edition, 1997.

[22] GB/T 20292-2006, Tumble Dryers for Household Use-Methods for Measuring the Performance, International 
Electrotechnical Commission (IEC), Geneva, Switzerland, 2006.

[23] D. Montgomery, Design and Analysis of Experiments, Wiley, Hoboken, NJ, USA, 7th edition, 2008.

[24] X. Bei, N. Chen, and S. Zhang, "On the complexity of trial and error," in Proceedings of the Forty-Fifth Annual ACM symposium on Theory of Computing STOC, D. Boneh, T. Rougarden, and J. Feigenbaum, Eds., pp. 31-40, ACM, New York, NY, USA, June 2013.

[25] https://en.wikipedia.org/wiki/Trial_and_error.

[26] J.-G. Lu and L.-Q. Song, "Discussion on performance test method of household tumble dryer RHH," Appliance, vol. 8, pp. 66-67, 2007.

[27] Q.-M. Ling, Study on the Thermal and Moisture Comfort of Clothing under the State of Sweat, Suzhou University, Suzhou, China, 2004. 


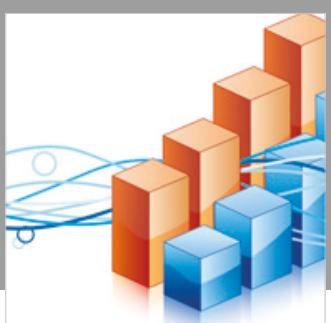

Advances in

Operations Research

\section{-n-m}
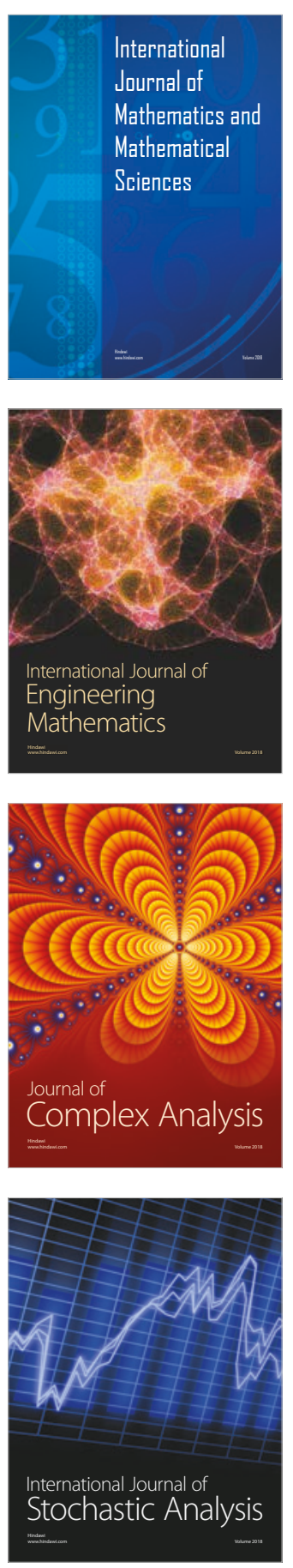
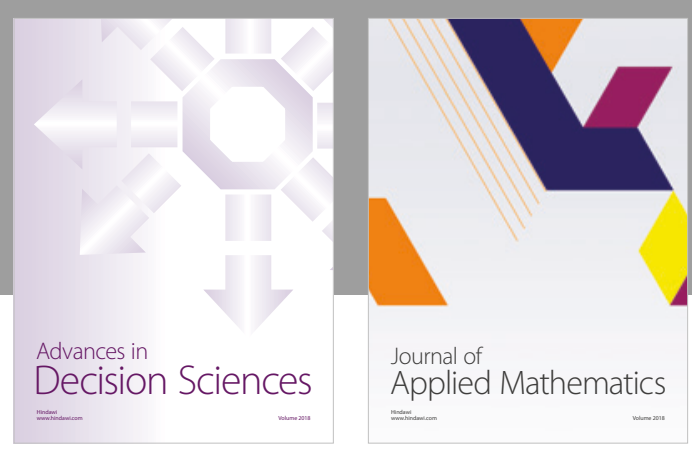

Journal of

Applied Mathematics
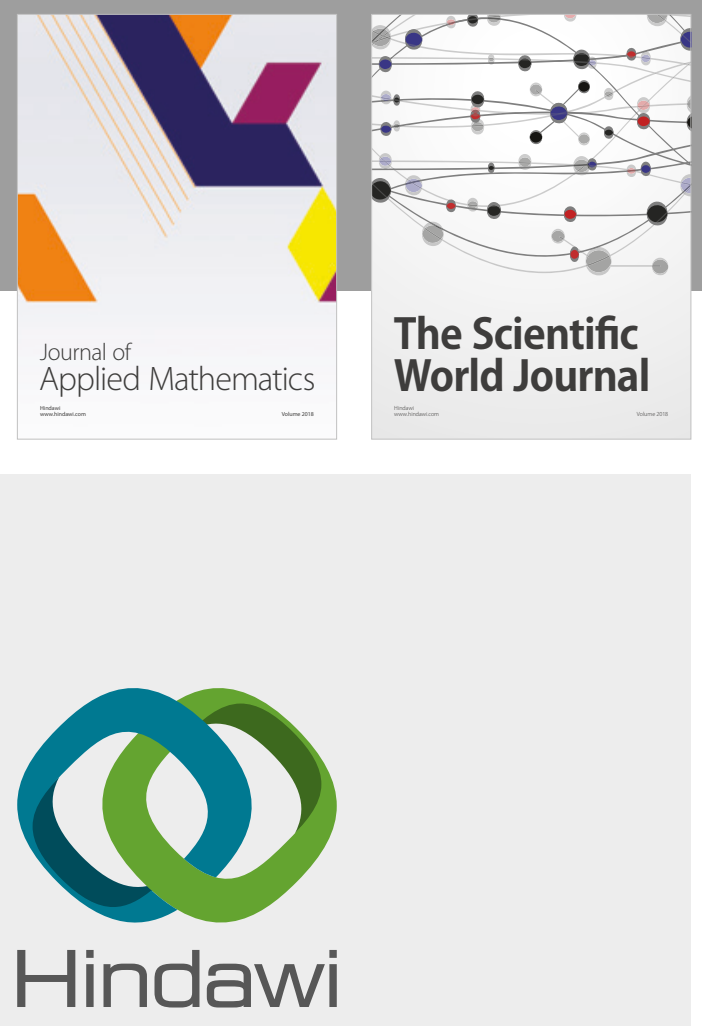

Submit your manuscripts at

www.hindawi.com

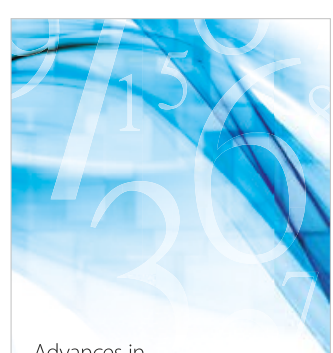

Advances in
Numerical Analysis
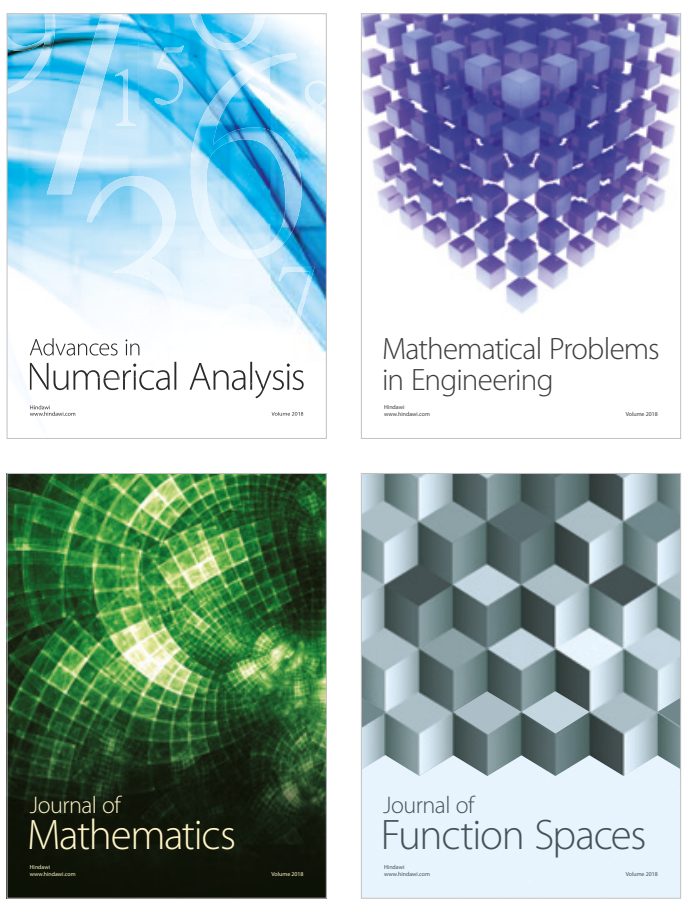

Mathematical Problems in Engineering

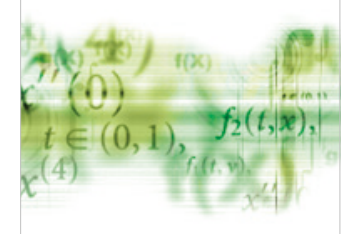

International Journal of

Differential Equations

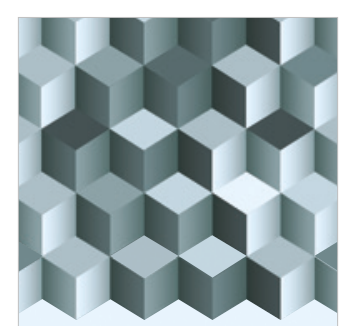

Journal of

Function Spaces

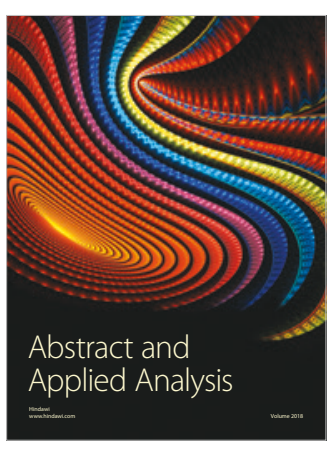

The Scientific

World Journal

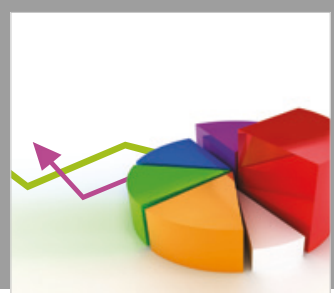

Journal of

Probability and Statistics
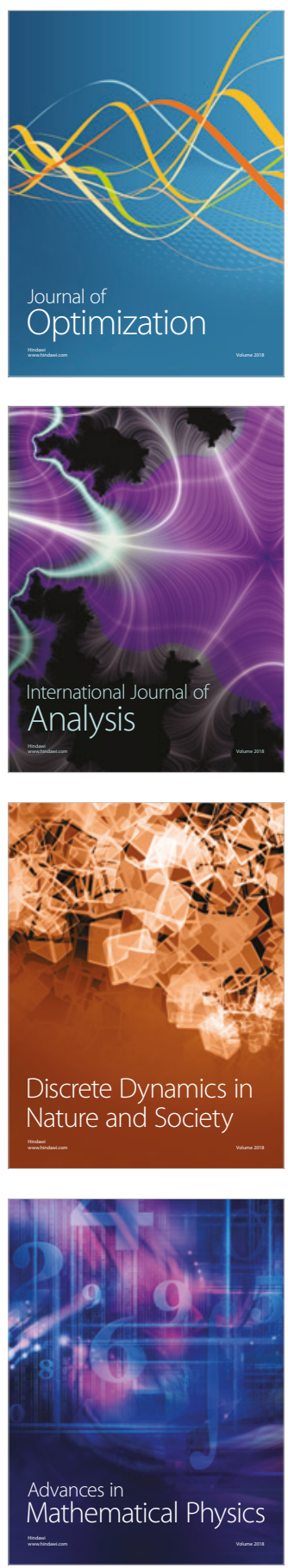